\title{
Die städtische Finanzautonomie im spätrömischen Reich*
}

\author{
Sebastian Schmidt-Hofner
}

Der schlanke, lediglich über einen kleinen bürokratischen Apparat gebietende Staat der Prinzipatszeit war nur funktionsfähig, weil er in den Städten des Reiches über eine gewachsene Struktur politischer Gemeinwesen verfügte, die die römische Herrschaft vor Ort sicherten, mehr oder minder eigenverantwortlich die meisten staatlichen Hoheitsfunktionen ausübten und der Zentralgewalt dabei insbesondere die Steuererhebung abnahmen. Der römische Staat der Prinzipatszeit war deshalb auf die Funktionsfähigkeit seiner munizipalen Substruktur angewiesen, und aus diesem Grunde ist das Verhältnis von Stadt und Staat für die Charakterisierung von Staatlichkeit und politischem Handeln in der römischen Kaiserzeit von eminenter Bedeutung.

Dies gilt ohne Einschränkung auch für das spätrömische Reich. Zwar bildete der spätantike Staat einen in bislang ungekanntem Maße komplexen Verwaltungsapparat aus, doch änderte dies nichts daran, daß der Staat für das lokale Regiment weiterhin subsidiärer politischer Strukturen bedurfte. In der Tat wurde die Stadt als basale politische Organisationseinheit flächendeckend - auch in Ägypten - erst durch Diokletians Reichsreform etabliert, und die Erhebung der Reichssteuern lag nun fast vollständig in der Hand der Städte. Allerdings hatte sich das Verhältnis von Stadt und Staat gegenüber der Prinzipatszeit erheblich gewandelt: Die Städte hatten viele Autonomierechte verloren, während die kaiserliche Bürokratie zunehmend in die Gemeinden hineinregierte und sie in mancherlei Hinsicht auf den Status eines Vollzugsorgans ohne eigenständigen politischen Handlungsspielraum reduzierte. Als besonders folgenreicher Aspekt dieser Entwicklung gilt der Forschung der Verlust der städtischen Finanzautonomie, also der eigenverantwortlichen

* Ich danke Malcolm Errington, Hans-Ulrich Wiemer, Christian Witschel und den Teilnehmern des Marbu rger Kolloquiums für ihre Anregungen zu diesem Beitrag. 
Verfügung der Gemeinden über ihre Einnahmen aus Steuern, Zöllen, Landbesitz und anderen Geldquellen. Seit Wilhelm Liebenams klassischer Arbeit über die „Städteverwaltung im Römischen Kaiserreiche" 1 besteht in der Forschung Konsens, daß die kaiserliche Finanzverwaltung bereits in der Prinzipatszeit eine Tendenz entwickelte, die Finanzwirtschaft der Städte ihrer Kontrolle zu unterwerfen, dabei insbesondere die Steuererhebung und das Zollwesen monopolisierte und die Gemeinden so ihrer wichtigsten Einnahmequellen beraubte. Die Städte seien deshalb finanziell immer mehr in die Abhängigkeit von kaiserlicher Unterstützung und dem Euergetismus reicher Bürger geraten und ansonsten darauf angewiesen gewesen, ihren Finanzbedarf durch das zunehmend Zwangscharakter gewinnende Liturgienwesen zu decken. Diese Entwicklung habe weitreichende Folgen gehabt, denn langfristig habe der Verlust der Finanzautonomie den Niedergang der Städte als selbstverwalteter politischer Gemeinwesen vorangetrieben und infolge dessen auch den finanziellen und sozialen Niedergang des Dekurionenstandes befördert. Auch andere Krisensymptome wie den Niedergang der monumentalen städtischen Bautätigkeit führt man auf diese Entwicklung zu rück. Der Verlust der städtischen Finanzautonomie gilt daher als ein wesentlicher Faktor für den Untergang der antiken Stadtkultur. ${ }^{2}$

Was in der Prinzipatszeit mit der zunehmenden Einflußnahme der kaiserlichen Finanzverwaltung auf die städtischen Finanzen ihren Anfang genommen habe, sei, so will es die Forschung, im Zuge der Stabilisierungs- und Zentralisierungsbestrebungen zu Beginn des vierten Jahrhunderts zum Abschluß gekommen, als der Kaiser, wahrscheinlich Konstantin, die städtischen Einnahmen nicht nur de facto, sondern auch de iure dem Staatseigentum einverleibt habe: Neben diversen kleineren Finanzposten habe dieser Konfiskationsakt die städtischen Ländereien einschließlich ihres Pachtzinsaufkommens, die Einnahmen aus lokalen Steuern und die Zolleinkünfte betroffen, also insbesondere auch die stetig fließenden und ertragreichsten Finanzquellen der Gemeinden. Bezeugt ist dieser Konfiskationsakt jedoch nicht, weshalb man zum Nachweis seiner Historizität eine Reihe indirekter Belege anführt. Deren wichtigste sind eine Konstitution Kaiser Julians, die man als umfassende Restitution der konstantinischen Konfiskation deutet, eine ephesische Inschrift aus der Regierungszeit Kaiser Valens', in der man

1 W. Liebenam, Städteverwaltung im Römischen Kaiserreiche, Leipzig 1900.

2 Zusammenfassend zuletzt J. H. W. G. Liebeschuetz, The Decline and Fall of the Roman City, Oxford 2001, 104-220; für den Zusammenhang mit dem Niedergang der Bautätigkeit s. z. B. B. Ward-Perkins, From Classical Antiquity to the Middle Ages: Urban Public Building in Northern and Central Italy, Oxford 1984, hier: $21 \mathrm{f}$. 
die Revokation der julianischen Maßnahme bzw. die erneute Enteignung der städtischen Einnahmen vorausgesetzt sehen möchte, und eine in mehreren Konstitutionen bezeugte Maßnahme der Kaiser Valentinian und Valens, die eine Aufteilung städtischer Einnahmen zwischen Staat und Gemeinden vorsieht und damit nach der gängigen Auffassung ebenfalls die Rekonfiskation belegt. Aus diesen und einigen weiteren Quellen konstruiert man dabei folgende Historie: Julian, der „Städtefreund“, habe Konstantins Konfiskationsakt rückgängig gemacht, doch sei diese Maßnahme Episode geblieben. Denn seine Nachfolger Valentinian und Valens hätten die für den Fiskus desaströse Restitution gleich zu Beginn ihrer Herrschaft widerrufen, als sie für die gewaltigen Verluste des gescheiterten Perserfeldzuges ihres Vorgängers aufkommen mußten. Fortan hätten die Städte also wieder für jede Ausgabe bei den Finanzbehörden vorstellig werden müssen. Die Langwierigkeit und Anfälligkeit dieses Verfahrens für Selbstbereicherungsversuche der Bürokratie habe, wie die ephesische Inschrift bezeuge, Valentinian und Valens im Laufe ihter Regierung von der Notwendigkeit überzeugt, den Städten einen gewissen eigenständigen Handlungsspielraum wiederzugeben: Obgleich der Fiskus weiterhin zwei Drittel der Einkünfte einzog, sei den Städten deshalb Anfang der 370er Jahre die eigenständige Verfügung über wenigstens ein Drittel davon überlassen worden, ohne daß jedoch das formale Eigentumsrecht und damit die Eingriffsmöglichkeit der kaiserlichen Verwaltung aufgegeben worden sei. Die Enteignung sei also nicht aufgehoben, ihre Folgen für die Gemeinden seien jedoch gemindert worden; diese Lösung habe sich als dauerhaft tragfähig erwiesen und deshalb fortan Bestand gehabt.

Das geschilderte Szenario besitzt in der Forschung kanonischen Rang, seit es A. H. M. Jones in seinem monumentalen Werk zur spätrömischen Verwaltungsgeschichte festgeschrieben hat. ${ }^{3}$ Und obwohl sich in bezug auf die Prinzipatszeit mittlerweile Kritik an der herkömmlichen Auffassung von der systematischen Unterwerfung städtischer Einkünfte unter staatliche Kontrolle vernehmen läßt, ist es nach wie vor die communis opinio der Forschung, $\mathrm{da}$ es im vierten Jahrhundert zu besagtem Konfiskationsakt gekommen sei. $^{4}$

3 A. H. M. Jones, The Later Roman Empire 284-602. A Social, Economic and Administrative Survey, 3 Bde., Oxford 1964.

4 Ausgangspunkt der Debatte ist heute J. H. W. G. Liebeschuetz' Aufsatz, The Finances of Antioch in the Fourth Century A.D., BZ 52, 1959, 344-356; die wichtigsten Beiträge seitdem: ders., Antioch: City and Imperial Administration in the Later Roman Empire, Oxford 1972, 149-155; ders., Decline (wie Anm. 2), 175-180; Jones, Later Roman Empire (wie Anm. 3), 732f, u. ö.; C. Lepelley, Les Cités de l'Afrique romaine au Bas-Empire, Bd. 1, Paris 1979, 61-72; ders., Temoignages épigraphiques sur la contrôle des finances muni- 
Lediglich ein einziger, Fergus Millar, hat einmal, wenn auch an entlegener Stelle, Bedenken angemeldet, ob die Quellen dieses Postulat wirklich rechtfertigen. ${ }^{5}$ Diese Bedenken sind, wie die folgende Untersuchung zeigen wird,

cipales par le gouvernement à partir du reigne de Dioclétien, in: Il capitolo delle entrate nelle finanze municipali in occidente ed in oriente. Actes Rome 1996, Rom 1999, 235 247; D. Simon, Das frühbyzantinische Emphyteuserecht, in: J. Modrzejewski/D. Liebs (Hgg.), Symposion 1977, Köln u. a. 1982, 365-422, hier: 379f.; G. Bonamente, Le città nella politica di Giuliano l'Apostata, AFLM 16, 1983, 33-96, hier: 46-59; A. Chastagnol, La legislation sur les biens des villes au IVème siècle à la lumière d'une inscription d'Ephèse, AARC 6, 1986, 77-104, hier: 85-89; F. Ausbüttel, Die Verwaltung der Städte und Provinzen im spätantiken Italien, Frankfurt/Main 1988, 65-69; P. Voci, Nuovi studi sulla legislazione romana tardoantica, Padua 1989, 97f,; R. Delmaire, Largesses sacrées et res privata. L'aerarium impérial et son administration du IVe au VIe siècle, Rom 1989, 276-282 + 644-657; G. D. Merola, Autonomia doganale nella tarda antichità intorno a CIL 3, 7151-7152, AARC 13, 2001, 277-292, hier: 285-293, sowie dies., Autonomia locale, governo imperiale. Fiscalità e amministrazione nelle province asiane, Bari 2001, 134139. Die exakte Datierung der Konfiskation ist umstritten: Liebeschuetz, Antioch, 152 plädiert für ein Datum vor 342 (gefolgert aus CTh 9, 17,2, s. unten); Chastagnol, AARC 6, 1986 für 356-358; Delmaire, Largesses sacrées, 650f. und Lepelley in: Finanze municipali, 243-245 für einen Zeitpunkt vor dem Jahr 358 (gefolgert aus CTh 4, 13, 5, s. unten). In bezug auf die Verwaltung des Gemeindelandes nach Valentinians Reform folgt Delmaire a. a. O. 652-655 nicht dem hier geschilderten Szenario der Forschung: Da es vor Justinian keinen Beleg dafür gibt, daß die Quotierungsregel auch im Osten angewandt wurde, will er dort das in I.Ephesos 42 belegte System individueller Zuweisungen (s. dazu später) annehmen. Im Westen habe sich die Quotierung zunächst auf die aus den städtischen Einnahmequellen gewonnenen Einkünfte bezogen, erst später (CJ 4, 61, 13, 431) auf die Verwaltung jener Quellen selbst; dies wiederum sei 451 (NMarc 3) auch im Osten angewandt worden. Dieses Szenario ist schon deswegen nicht überzeugend, weil Delmaire in bezug auf die vectigalia diese Änderungen nicht annimmt, sondern von einem seit den 370er Jahren in allen Reichsteilen einheitlichen und unveränderten System ausgeht. Vor allem aber verkennt es die Eigenart der einschlägigen juristischen Quellen: ihre Entstehung in Reaktion auf konkrete Probleme und die Tatsache, daß nur die wenigsten Rechtsentscheide überliefert sind, bringt den methodischen Vorbehalt mit sich, daß die juristische Überlieferung kein vollständiges Bild der Rechtsentwicklung liefert. Dies aber bedeutet, daß auch ein erst im fünften Jahrhundert zum ersten Mal explizit belegtes Rechtsinstitut schon längst in Gebrauch gewesen sein kann. Das gilt über die hier behandelten juristischen Quellen hinaus für alle Kaiserkonstitutionen der Spätantike: Vgl. dazu und zu anderen Aspekten der Interpretation spätrömischer Kaiserkonstitution die 2006 in der Reihe „Vestigia" erscheinende Marburger Dissertation des Verfassers mit dem Titel „Kaiser und Gesetz. Der Regierungsstil des spätrömischen Kaisers im Spiegel des Codex Theodosianus: das Beispiel Valentinians I.“.

5 F. Millar, Italy and the Roman Empire: Augustus to Constantine, Phoenix 40, 1986, 295 312, hier: 305f.; auch in: ders., Rome, the Greek World and the East, Bd. 2: Government, Society and Culture in the Roman Empire, Chapel Hill - London 2004, 372-398, hier: 384. Auch Simon in: Symposion 1977 (wie Anm. 4), 379f. und Ausbüttel, Verwaltung 
vollauf berechtigt. Denn im folgenden wird anhand einer vollständigen Revision des Quellenmaterials nachgewiesen werden, daß die Quellenlage viel einfacher zu deuten ist, wenn man akzeptiert, daß es weder unter Konstantin noch unter Valentinian noch zu irgendeinem anderen Zeitpunkt eine globale Konfiskation städtischen Eigentums gegeben hat. Im Gegenteil wird sich sogar zeigen, daß im vierten Jahrhundert - nämlich in der bereits erwähnten, bislang aber mißinterpretierten „Aufteilung“ der städtischen Gelder zwischen Stadt und Staat unter Valentinian und Valens - zum ersten Mal in einer langen Geschichte staatlicher Kontrollversuche eine explizite Zusicherung der freien Verwendung städtischer Einnahmen durch die Gemeinden bezeugt ist. Da die Quellen umgekehrt jedoch ebensowenig Zweifel daran lassen, daß die kaiserliche Bürokratie in der Spätantike zumindest partiell in das städtische Finanzwesen eingriff, ergibt sich die Notwendigkeit, das Zusammenspiel von kaiserlicher Bürokratie und munizipaler Selbstverwaltung im Bereich der

(wie Anm. 4), 66 weisen darauf hin, daß der Quellenbefund eine Globalkonfiskation unter Konstantin nicht hergibt, ziehen sie jedoch nicht grundsätzlich in Zweifel, sondern erklären die Quellenlage mit einer graduellen oder unsystematischen Konfiskation. Auch J. Durliat, Les finances publiques de Dioclétien aux Carolingiens (282-889), Sigmaringen 1990, 143-145 meint, es habe nie eine Konfiskation gegeben; außerdem habe sich die Quotierungsregel nicht auf städtische Einkünfte, sondern auf die Steuereinnahmen des Reiches bezogen. Die These ist eine Konsequenz seiner von W. Goffart, Caput and Colonate. Towards a History of Late Roman Taxation, Toronto 1974 übernommenen, in: J. Durliat, Le salaire de la paix sociale dans les royaumes barbares, in: H. Wolfram/A. Schwarcz (Hgg.), Anerkennung und Integration: zu den wirtschaftlichen Grundlagen der Völkerwanderungszeit (400-600). Symposion Stift Zwettl 1986, Wien 1988, 21-72 zuerst vertretenen Auffassung, die Barbaren hätten nicht Ländereien zugewiesen bekommen, sondern Steuergelder, und zwar zwei Drittel des Gesamtaufkommens, während das verbleibende Drittel an die Städte ging. Dieses Arrangement sei der schon seit Valentinian bestehenden Regelung gefolgt, die deswegen aber eben auf Staatseinnahmen, nicht auf städtische Einkünfte bezogen gewesen sei. Gegen die Kritik von W. Liebeschuetz, Cities, Taxes and the Accomodation of the barbarians: the theories of Durliat and Goffart, in: W. Pohl ( $\mathrm{Hg}$.$) , Kingdoms of the Empire. The Integration of Barbarians in Late$ Antiquity, Leiden u. a 1997, 135-151, will J. Durliat, Cité, impôt et intégration des barbares, ebd. 153-179, nun seine zuvor nur postulierte These durch Quellen untermauern, die zeigen sollen, daß die Quotierungsregel sich nicht auf städtische Einkünfte bezogen habe. Seine Argumente sind jedoch unhaltbar: Die wichtigsten Einwände hat bereits Liebeschuetz a. a. O. 150f, benannt; hier sei noch darauf hingewiesen, daß der Behauptung Durliats, reditus rei publicae (z. B. in CTh $14,3,7$ ) sei der Terminus technicus für Staatseinnahmen, Dutzende von Belegen vor allem aus dem Bereich der Domänenverwaltung entgegenstehen, die zweifelsfrei zeigen, $\mathrm{da} \beta$ der canon von fundi rei publicae eindeutig das Pachtzinsaufkommen von (ehemals) städtischem Besitz meint. Außerdem ignoriert er CTh 5, 14, 35 oder CJ 4, 61, 13, wo die durch Valentinians Quote aufgeteilten städtischen Einkünfte unmißverständlich von Staatseinnahmen abgegrenzt werden. 
Finanzwirtschaft jenseits der Konfiskationsthese neu zu definieren. Diese Neudefinition wird sich nicht auf die Spätantike beschränken. Denn mit dem angeblichen Konfiskationsakt zum Zeitpunkt der Epochenwende von der Prinzipatszeit zur Spätantike fällt auch die herkömmliche Zäsur in der Geschichte der städtischen Finanzwirtschaft, so daß das Verhältnis von Stadt und Staat im Bereich der Finanzwirtschaft sich nur in der Gesamtschau über die sechshundertjährige Geschichte des römischen Kaisertums beschreiben läßt. Ein wesentliches Kapitel der spätantiken Stadtgeschichte wird dabei in gänzlich neuem Licht erscheinen.

\section{Julians Restitutionsedikt}

An den Iden des März $362^{6}$ erließ Kaiser Julian in Konstantinopel eine Konstitution an den Prätoriumspräfekten von Oriens, Salutius Secundus, von der ein Fragment im „Codex Theodosianus" als CTh 10, 3, 1 überliefert ist:

Possessiones publicae civitatibus iubemus restitui ita ut iustis aestimationibus locentur, quo cunctarum possit civitatium reparatio procurari.

Wir befehlen, daß den Städten Ländereien in öffentlichem Besitz zurückerstattet werden, und zwar so, daß sie nach einer gerechten Abschätzung zugeteilt werden, damit so die Wiederherstellung vieler Städte besorgt werden kann. ${ }^{7}$

Eine Gruppe von Ländereien, die als possessiones publicae bezeichnet werden, soll also, so befiehlt der Kaiser, den Städten zurückerstattet werden; diese Restitution wird mit der Auflage verbunden, daß die aus ihrer Verpachtung gewonnenen Einkünfte für Baumaßnahmen genutzt werden. Dieselbe Maßnahme dürfte auch Ammian meinen, wenn er berichtet, Julian habe den Städ-

6 In der Literatur liest man meist das von O. Seeck, Regesten der Kaiser und Päpste für die Jahre 311 bis 476 n. Chr. Vorarbeit zu einer Prosopographie der christlichen Kaiserzeit, Stuttgart 1919, 134 und 210 emendierte Datum des 13. März 362. Seeck wollte die überlieferte Datierung auf die Iden des März deswegen verbessern, weil vom 13. März eine Reihe anderer Konstitutionen Julians stammt, die in irgendeiner Weise mit dem Thema „Stadt" befaßt sind. Keine von ihnen ist jedoch thematisch so eng verwandt (CTh 11, 16, 1 betrifft Liturgien, 12, 1, 50 Steuerimmunitäten), daß die Emendation des Datums von CTh 10, 3, 2 zwingend wäre.

7 Übersetzung (wie auch im folgenden) durch den Verfasser. 
ten vectigalia cum fundis wiedergegeben, also Ländereien samt ihren Einkünften aus dem Pachtzins. ${ }^{8}$

Gemeinhin geht man davon aus, daß in diesen beiden Quellenbelegen eine globale Restitution des städtischen Grundbesitzes überliefert ist, mit der Julian, der Förderer der Städte und der munizipalen Selbstverwaltung, die Enteignung dieser Ländereien im Zuge der Konfiskation der städtischen Einnahmequellen unter Konstantin habe rückgängig machen wollen. Da ein einschlägiger Konfiskationsakt wie gesagt nicht überliefert ist, gilt Julians Erlaß als einer der Hauptbelege dieser Globalenteignung. Bereits vor einigen Jahren hat jedoch Hans-Ulrich Wiemer gewichtige Einwände gegen diese Deutung vorgebracht. ${ }^{9}$ Wiemer macht zum einen geltend, daß die vermeintlich massive Kursänderung bei Ammian lediglich in einer beiläufigen Notiz Erwähnung findet, im „Prosphonetikos"des Libanios (der immerhin ein ebenso glühender Verfechter munizipaler Rechte wie Bewunderer Julians war) nur en passant vermerkt ist und im „Epitaphios" nicht einmal einer Erwähnung für würdig erachtet wird. ${ }^{10} \mathrm{Zum}$ anderen führt Wiemer eine ganze Reihe von Belegen aus literarischen, epigraphischen und juristischen Quellen an, die zweifelsfrei belegen, daß die Städte auch vor dem „Restitutionsakt“ Julians Eigentumsrechte an Grundbesitz und anderen Einkommensquellen besaßen und ausübten:

So belegen die unter der Bezeichnung „Landlisten“ geläufigen Steuerdokumente aus dem Hermopolites in den 350er Jahren mehrmals die Verpach-

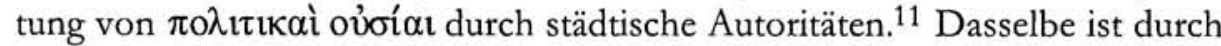
Libanios für das syrische Antiocheia belegt, als er Anfang der 360er Jahre, noch unter Kaiser Constantius II., für die Verpachtung von Gemeindeland an die städtischen Lehrer plädierte; ${ }^{12}$ in beiden Fällen konnten die Städte also ein wichtiges Besitzrecht ausüben. Weiterhin berichtet Ammian, der Bischof von Alexandreia habe Constantius die Konfiskation von städtischen Immobilien im ägyptischen Alexandreia insinuiert; ${ }^{13}$ daraus läßt sich schließen, daß

8 Amm. 25, 4, 15; der Einwand, vectigal könne nicht den Pachtzins meinen, ist von H.-U. Wiemer, Libanios und Julian: Studien zum Verhältnis von Rhetorik und Politik im vierten Jahrhundert n. Chr., München 1995, 103 Anm. 94 mit guten Gründen widerlegt worden. Außerdem meint vectigal in Verbindung mit fundi auch anderswo den Pachtzins: so z. B. in CTh 5, 15, 14; 5, 15, 15; 5, 15, 17.

9 Wiemer, Libanios (wie Anm. 8), 102-107.

10 Lib. Or. 13,45 f.

11 P. Landlisten G 184; 235; 271; F 127; 137; 474.

12 Lib. Or. 31, 16-20.

13 Amm. 22, 11, 6. 
sie bis dahin in städtischem Eigentum gelegen haben müssen. Auch über eigene Steuertitel konnten die Städte offenbar verfügen: Im Jahre 331 bestätigte ein epigraphisch überlieferter Brief Konstantins der Gemeinde Orkistos in Phrygien, daß sie der Stadt Nakoleia, zu deren Stad tterritorium sie bis kurz zuvor gehört hatte, keine Abgaben mehr leisten müsse, da sie mittlerweile selbst Stadtrecht erlangt hatte. ${ }^{14}$ Der Brief reagiert auf eine Klage von Orkistos, weil Nakoleia weiterhin Tribut einforderte - offenbar sah die Stadt Nakoleia sich also auch nach der vermeintlichen Enteignung unter Konstantin dazu berechtigt, in eigenem Namen Abgaben zu erheben.

Diese Quellen zeigen unzweifelhaft, daß von einer vollständigen Konfiskation städtischer Ländereien und anderer Einnahmequellen zu irgendeinem Zeitpunkt vor Julian keine Rede sein kann. Daraus läßt sich folgern, daß die Konfiskation nie universaler Natur war. Die Quellenlage erlaubt aber einen noch weitergehenden, bislang nicht gesehenen Schluß: nämlich den, daß die Historizität des Enteignungsaktes grundsätzlich in Zweifel gezogen werden kann. Diese Zweifel sind vollauf berechtigt, denn nicht eine einzige Quelle vermag ihn direkt oder indirekt zu belegen. Weder unter Diokletian noch unter Konstantin gibt es dafür irgendeinen positiven dokumentarischen oder literarischen Beleg, obwohl eine beiden Herrschern feindlich gesonnene historiographische Tradition existiert, die sich eine so einschneidende Maßnahme sicherlich nicht hätte entgehen lassen: Laktanz geht gleich zweimal ausführlich und polemisch auf die Fiskalpolitik Diokletians ein und zählt dabei auch deren angeblich desaströse Folgen für die Städte auf. ${ }^{15}$ Eine Globalenteignung ihrer Einkünfte hätte dabei nicht fehlen dürfen. Einen ganzen Kata$\log$ fiskalpolitischer Untaten Konstantins gegenüber den Städten verzeichnet Zosimos; auch bei ihm verlautet jedoch nichts von der doch bestens zur Aussageabsicht des Autors passenden Enteignung ihrer Ländereien und Gefälle. ${ }^{16}$ Bezeugt ist unter Konstantin und seinen Nachfolgern lediglich eine groBe Zahl von Konfiskationsakten an den Besitzungen heidnischer Heiligtümer, die zuweilen in städtischer Verwaltung lagen, ${ }^{17}$ doch stehen diese Maßnahmen in einem spezifischen politischen und religiösen Kontext und dürfen deshalb nicht als Beleg für eine globale Enteignung sämtlicher städtischer Einkommensquellen in Anspruch genommen werden.

14 MAMA VII 305 \$III; vgl. zuletzt den Kommentar von D. Feissel, L'adnotatio de Constantin sur le droit de la cité d'Orkistos en Phrygie, AnTard 7, 1999, 255-267.

15 Lact. Mort. pers. 7 und 23.

16 Zos. 2, 38, 4.

17 Vgl. die unten in Anm. 24 genannte Literatur. 
In der Forschung wird mangels direkter Belege eine Reihe von Zeugnissen aus der ersten Hälfte des vierten Jahrhunderts als indirekte Belege für die Enteignung namhaft gemacht. Diese Interpretation der Zeugnisse hält jedoch einer Überprüfung in keinem Fall stand. In der Konstitution CTh 4, 13, 5 bestätigte Kaiser Constantius II. einem Vikar von Africa im Jahre 358 die offenbar schon länger gebräuchliche Regelung, daß den Städten seines Sprengels ein Viertel der vectigalia zur Reparatur öffentlicher Gebäude zur Verfügung gestellt werden könne. Bei diesen vectigalia, so lautet die gängige Interpretation des Dokumentes, handele es sich um städtische Zolleinnahmen, die folgerichtig zu irgendeinem Zeitpunkt vorher konfisziert worden sein müßten. Dieser Schluß ist jedoch keineswegs zwingend. Denn einmal davon abgesehen, daß einem Erlaß, der seinem Adressaten zufolge zunächst einmal ausschließlich im Vikariat Africa Geltung besaß, keine reichsweite Regel zu entnehmen ist, gibt es keinerlei Anhaltspunkt dafür, daß hier städtische vectigalia gemeint waren. Genauso gut könnte die Formulierung beispielsweise Einkünfte aus Reichszöllen im Sinn haben, die den Städten im Zuge kaiserlicher Munifizenz überwiesen werden sollten. ${ }^{18}$ Derselbe Einwand entkräftet auch den Aussagewert einer Notiz in der Konstitution CTh 9, 17, 2, die den Statthaltern im Jahre 342 die Verwendung von Spolien aus Grabmälern für Baumaßnahmen untersagt, „da sie diese aus den vectigalia und anderen titult ${ }^{* 19}$ bestreiten sollten: In wessen Namen diese vectigalia erhoben wurden, ist auch dieser Aussage nicht zu entnehmen.

Ein Indiz für die Konfiskation städtischer Liegenschaften will man schließlich auch in einem Brief des Libanios aus der Regierungszeit Julians entdeckt haben, in dem er die Restituierung eines Gebäudes an die Stadt Tyrus erwähnt, das durch Konstantin oder Constantius II. an einen Günstling verschenkt worden war. ${ }^{20}$ Eine vorangehende globale Konfiskation des städtischen Grundbesitzes setzt freilich auch das nicht voraus. Denn abgesehen davon, daß unbekannte Hintergründe ein punktuelles kaiserliches Eingreifen in das städtische Vermögen rechtfertigen mochten, gibt es auch hier andere

18 Vectigal kann in der spätrömischen Verwaltungssprache unspezifisch für Abgaben jeglicher Art stehen (s. z. B. oben Anm. 8), doch in der weit überwiegenden Zahl meint der Begriff Zollabgaben. Eine terminologische Differenzierung zwischen Lokal- und Reichszöllen läßt sich dabei nicht feststellen: Vgl. die Wortuntersuchungen bei Delmaire, Largesses sacrées (wie Anm. 4), 275f. und D. Nonnis/C. Ricci (Hgg.), Vectigalia municipali ed epigrafia: un caso dell' Hirpinia, in: Finanze municipali (wie Anm. 4), 41-59, hier: $56-$ 59, sowie bei Merola, AARC 13, 2001 (wie Anm. 4), 285-293.

19 ... nam ex vectigalibus vel aliis titulis aedificare debuerunt.

20 Lib. Ep. 828; vgl. zu den Einzelheiten des Vorgangs Liebeschuetz, Antioch (wie Anm. 4), 152 Anm. 1. 
Erklärungsmöglichkeiten: Der Staat nahm, wie noch zu zeigen sein wird, unabhängig von der Frage nach dem Eigentum an den städtischen Einkommensquellen immer wieder Einfluß auf die Verpachtung städtischer Ländereien. Außerdem war die hier betroffene Immobilie vielleicht gar nicht in städtischem Grundbesitz gelegen, sondern stammte aus dem unter Julian restituierten Eigentum der Tempel, das sich häufig in der Verwaltung der Städte befand. ${ }^{21}$

Keiner der angeblichen indirekten Belege für eine Konfiskation in der ersten Hälfte des vierten Jahrhunderts erzwingt also die Annahme einer Globalenteignung zu irgendeinem Zeitpunkt vor der Regierungszeit Julians. Ergänzt man dieses Ergebnis um die zuvor genannten Zeugnisse für das Fortbestehen einer eigenständigen Verfügung der Städte über Liegenschaften und Steuertitel, so ergibt sich daraus, daß die These einer Konfiskation im frühen vierten Jahrhundert nicht nur jeden positiven Belegs ermangelt, sondern im Gegenteil sogar einer ganzen Reihe von Quellen direkt widerspricht. Daß die Forschung trotz dieser Quellenlage an der These der Globalenteignung festhält, erklärt sich daraus, daß die Zeugnisse unter der Prämisse gelesen werden, unter Julian habe eine umfassende Restitution der städtischen Liegenschaften und anderer Einkommensquellen an die Gemeinden stattgefunden (was das Postulat eines vorangehenden, ebenso umfassenden Konfiskations-

21 Zuweilen liest man als Argument für die Existenz des Konfiskationsaktes, daß Constantius II. im Jahre 355 durch Julian für Wohltaten gegenüber den Städten gepriesen worden sei, die unter seinen Vorgängern Mangel gelitten hätten (Iul. Or. 1, 42D-43A). Aus diesem topischen Herrscherlob geht freilich nicht mehr als ein vager Hinweis auf kaiserlichen Euergetismus hervor, sicher jedoch kein zwingender Schluß auf eine vorangehende Konfiskation. In CJ 11, 42, 1 (Diokletian) wird die Umwidmung von Geldern, die Spiele finanzieren sollten, für Baumaßnahmen angeordnet; wenn es sich dabei nicht ohnehin um kaiserliche Z uschüsse handelt, impliziert das zwar eine Einflußnahme des Kaisers auf die Verwendung städtischer Finanzen, nicht aber deren totale Enteignung (vgl. aber Delmaire, Largesses sacrées [wie Anm. 4], 649 und Lepelley in: Finanze municipali [wie Anm. 4], 242-244). Dasselbe gilt für die zahlreichen Belege, die die Kontrolle städtischer Baumaßnahmen durch die Statthalter bezeugen, darunter auch eine unten noch zu behandelnde Inschrift aus Chalkis aus dem Jahr 359, wo der Statthalter die Verwendung

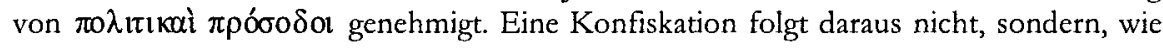
später noch ausgeführt werden wird, lediglich eine Aufsichtsfunktion. Lepelley a. a. O. 244f. schließlich will in einem dakischen Meilenstein (AE 1992, 1510), der mit den Worten recuperata re publica [---] in antiquam ce(n) suram dignitatemque reuocauit endet, die Restitution der fundi rei publicae durch Julian bestätigt sehen. Dieser Schluß ist nicht nachvollziehbar. Auch der Bauboom in Afrika seit 364, den ders., Cités de l'A frique (wie Anm. 4), $101-106$ an den julianischen Restitutionsakt knüpfen wollte, ist an sich kein hinreichender Beweis für die Konfiskation und Restitution sämtlicher städtischer Einnahmequellen. 
aktes nach sich zieht). Gibt man jedoch diese, wie die Untersuchung gezeigt hat, durch nichts gestützte Prämisse auf, folgt daraus, daß Julians Maßnahme nicht der Revokation einer globalen Konfiskation unter Konstantin gedient haben kann - weil es diese nie gegeben hat.

Diese Lösung hat den unzweifelhaften Vorzug, die Quellenlage ohne die Annahme eines Totalverlusts in der Überlieferung der angeblichen Konfiskation und ohne das zweifelhafte Zeugnis vermeintlicher indirekter Belege erklären zu können. Wie ist dann jedoch der „Restitutionsakt“ Julians zu deuten? Wiemer hat den überzeugenden Vorschlag gemacht, daß Julians Maßnahme nicht der Gesamtheit des städtischen Grundeigentums galt, sondern lediglich die Besitzungen der enteigneten städtischen Heiligtümer betraf. Die beiden Quellenbelege lassen diese Interpretation zu: Die Konstitution CTh 10, 3, 1 bezeichnet die betroffenen Ländereien mit der unspezifischen Vokabel possessiones publicae, die auch das Tempelland meinen kann, ${ }^{22}$ Ammian spricht lediglich von vectigalia cum fundis, also vom Pachtzinsaufkommen nicht näher eingegrenzter Ländereien. Daß die betroffenen Liegenschaften in der Konstitution nicht exakt benannt werden, stellt kein Gegenargument dar: Die mangelnde Präzision mag sich aus der fragmentarischen Überlieferung des Textes erklären, könnte aber auch dem Umstand geschuldet sein, daß die Kaiserkonstitutionen zumeist in Reaktion auf konkrete Anliegen - hier vielleicht eine Petition einer oder mehrerer Städte - entstanden, bei denen dem Verfasser ebenso wie dem oder den Adressaten der kaiserlichen Verlautbarung deren konkreter Sachbezug geläufig war. Nicht zuletzt gilt es auch zu beachten, daß die sachliche Prägnanz in dieser Textgattung häufig der notorischen Neigung spätrömischer Hofjuristen zum Opfer fiel, die Begrifflichkeit der Verwaltungssprache ihrem sprachlichen oder literarischem Geschmack anzupassen.

Überzeugungskraft gewinnt Wiemers Interpretation dadurch, daß die Restitution des Tempellands sich in einen bestens bezeugten historischen Kontext einfügt und Julians Maßnahme dadurch überdies einen - im Unterschied zu dem hinsichtlich seiner Originaliät und Intensität bezweifelbaren

22 Vgl. A. H. M. Jones, The Greek City: From Alexander to Justinian, Oxford 1940, 227229; A. Bowman, The Town Councils of Roman Egypt, Toronto 1971, 97f. für Quellen, die die städtische Verwaltung von Tempelgütern belegen und damit die Bezeichnung von Tempelland als possessiones publicae rechtfertigen; vgl. jetzt auch A. d'Hautcourt, Les cités grecques et les revenus de leurs sanctuaires. L'exemple de l'Asie Mineure à l'époque romaine, in: Finanze municipali (wie Anm. 4), 249-260. 
Programm zur „Städteförderung“23 - klar konturierten und überzeugenden Motivationszusammenhang gewinnt. Denn anders als die vermeintliche Globalenteignung sind Konfiskationen von Tempelbesitz unter Konstantin und seinen Nachfolgern reichlich bezeugt. ${ }^{24}$ Und daß gerade Julian diese Eingriffe rückgängig machen wollte, erklärt sich im Zusammenhang seiner paganen Restaurationspolitik von selbst. In der Tat werden vor diesem Hintergrund auch die lediglich beiläufigen Bemerkungen eines Ammian oder Libanios verständlich: Denn die Religionspolitik Julians einschließlich der Renaissance der Tempel würdigen jene beiden Bewunderer des Kaisers zweifellos in angemessener Weise, während die Rückgabe ihres Grundbesitzes in diesem Zusammenhang nur ein administratives Detail darstellte. Ebenjene Passage in Libanios' „Prosphonetikos" liefert im übrigen noch ein weiteres, starkes Argument dafür, daß Julians Restitution nicht das gesamte Gemeindeland betraf, sondern nur den Tempelbesitz. Denn ihr Resümee läßt an der religionspolitischen Motivation der Maßnahme keinen Zweifel: „Die Verehrung in den Tempeln“, so heißt es dort, „wieder einzuführen, nachdem sie unterdrückt worden war, ist nicht weniger, als sie zum ersten Mal einzuführen“. ${ }^{25}$

\section{Die Quotierungsregel}

Für die Frage nach den Eigentumsverhältnissen an den städtischen Finanzquellen bleibt also festzuhalten, daß es für die gesamte erste Hälfte des vierten Jahrhunderts bis zum Tode Julians keinen einzigen Quellenbeleg für den von der Forschung postulierten globalen Konfiskationsakt städtischen Eigentums gibt. Wie aber stellt sich das Problem in der zweiten Jahrhunderthälfte und darüber hinaus, im fünften und sechsten Jahrhundert, dar? Gab es, wie die Forschung meint, eine (erneute) Konfiskation gleich zu Beginn der Regierung Valentinians und Valens'? Gibt es aus dieser Zeit einen Quellenbeleg für einen solchen Enteignungsakt, sei er vor oder nach Julian? Die Antwort muß, wie der folgende Abschnitt zeigen wird, auch hier negativ ausfallen.

23 Vgl. die Untersuchung von E. Pack, Städte und Steuern in der Politik Julians: Untersuchungen zu den Quellen eines Kaiserbildes, Brüssel 1986, 57-259.

24 Quellen bei Delmaire, Largesses sacrées (wie Anm. 4), 641-643 + 648-656; vgl. zuletzt D. Metzler, Ökonomische Aspekte des Religionswandels in der Spätantike: Die Enteignung der heidnischen Tempel seit Konstantin, Hephaistos 3, 1981, 27-40; B. Enjuto Sánchez, Las disposiciones judiciales de Costantino y Juliano a propósito de las tierras de los templos paganos, Gerión 18, 2000, 407-423.

Lib. Or. 13, 46. 
Am 7. September $374^{26}$ stellte Kaiser Valentinian in Mainz einen Erlaß an den Prokonsul von Africa, Paulus Constantius, aus, der im „Codex Theodosianus" als Konstitution 4, 13, 7 überliefert ist:

Ex reditibus rei publicae omniumque titulorum ad singulas quasque pertinentium civitates duae partes totius pensionis ad largitiones nostras perveniant, tertia probabilibus civitatum deputetur expensis.

Von den Einkünften der Stadt und allen Abgaben, die einzelnen Städten gehören, sollen zwei Teile der Gesamteinnahmen an die sacrae largitiones gehen, der dritte aber soll den billigenswerten Ausgaben der Städte zur Verfügung gestellt werden.

Das Dokument setzt also einen Schlüssel fest, nach dem gewisse, hier nicht näher spezifizierte städtische Einkünfte zwischen Gemeinde und Fiskus aufgeteilt werden sollen. Um welche Einkünfte es sich dabei handelte, geht aus

26 Die überlieferte Subskription der Konstitution verzeichnet den Ausstellungsort "Mainz" sowie „7. September 375“, wobei weder ein datum noch ein propositum oder sonst ein Datierungsvermerk überliefert ist. Da die Einfügung eines datum aus chronologischen Gründen in diesem Jahr ausscheidet (im Herbst 375 stand Valentinian an der Donau, der Adressat Paulus Constantius war tot: s. PLRE I, 227 s. v. Constantius 11), ein propositum ohnehin (Konstitutionen an den Prokonsul von Afrika werden nicht in Mainz proponiert), bleibt nur ein datum und die Verbesserung der Jahresangabe in das Jahr 374. Paläographisch ist das einleuchtend, da im Jahr 375 mit einem Postkonsulat von 374 datiert wurde und die Überlieferung daher leicht gestört worden sein kann. Außerdem ist bekannt, daß sich Valentinian im Jahr 374 in Mainz aufhielt, weil er dort einen Friedensvertrag mit dem Alamannenkönig Macrianus schloß: Amm. 30, 3, 4 (das Jahresdatum geht unzweifelhaft aus 30, 3, 1 hervor). Die Konstitution muß also am 7. September 374 in Mainz gegeben worden sein: so auch Seeck, Regesten (wie Anm. 6), $86+244$ sowie F. Pergami, La legislazione di Valentiniano e Valente 364-375 (Materiali per una palingenesi delle costituzioni tardo-imperiali 2, 4), Mailand 1993, 636f. Pergami (619f.) folgert daraus, daß dann auch das Datum der gleich zu behandelnden Konstitution CTh 15, 1, 18 verbessert werden müsse, die ein propositum am 26. Januar 374 verzeichnet; da ihre Anordnungen die in CTh 4, 13, 7 festgehaltenen Maßnahmen jedoch bereits voraussetzten, müsse man sie nach CTh 4, 13, 7 datieren, wofür sich wiederum die Verbesserung der Konsulatsangabe in das Postkonsulat 375 anbiete. Das ist deswegen nicht zwingend, weil CTh 4, 13, 7, wie die Untersuchung zeigen wird, selbst ein Implementierungszeugnis war, das die in ihm geschilderte Verfahrensreform in einem konkreten Fall bestätigte. Da die Datierungskriterien von CTh 15, 1, 18 aber in sich vollkommen schlüssig sind, sollten sie nicht willkürlich verändert werden; das spätere Datum von CTh 4, 13, 7 kann wie gesagt anderweitig erklärt werden. Es bleibt für CTh 15, 1, 18 also bei dem überlieferten propositum am 26. Januar 374. 
der Parallelüberlieferung hervor: Am 26. Januar $374^{27}$ wurde in Sirmium die Konstitution CTh 15, 1, 18 an den Prätoriumspräfekten von Italien, Afrika und dem Illyricum, Sextus Petronius Probus, proponiert. Die Konstitution behandelt die Frage, was zu tun sei, wenn bei der Finanzierung von Bauvorhaben, die aus städtischen Geldern bestritten werden, Engpässe auftreten:

Si civitatis eius res publica tantum in tertia pensionis parte non habeat, quantum coeptae fabricae poscat inpendium, ex aliarum civitatum rei publicae canone praesumant, tertiae videlicet portionis.

Wenn das Stadtvermögen dieser Stadt im dritten Teil der Einkünfte nicht soviel besitzt, wieviel die Kosten des angefangenen Bauwerks erfordern, sollen sie das aus den Pachteinnahmen des Haushalts anderer Städte in Anspruch nehmen, allerdings nur aus dem dritten Teil.

Die Konstitution richtet also, wahrscheinlich in Reaktion auf einen konkreten Fall, eine Art von „Finanzausgleich“ zwischen den Städten ein, nach welchem Einnahmen einer Stadt für Bauprojekte einer anderen verwandt werden dürfen, ${ }^{28}$ begrenzt aber die Zugriffsmöglichkeit im Interesse der betroffenen Städte auf ein Drittel des canon. Für das Verständnis der valentinianischen Quotierungsregel bedeutsam ist, daß eine Stadt für Baumaßnahmen nur über ein Drittel ihrer pensiones verfügen kann; ein Dossier von Konstitutionen aus dem Jahr 395, in dem diese Bestimmung - wiederum in bezug auf ein konkretes Problem - bestätigt wird, zeigt, daß der Begriff pensio eine Einnahme bezeichnet, die, wie es dort heißt, „,von den Liegenschaften und Ländereien einer Stadt als jährliche Abgabe erbracht wird". ${ }^{29}$ Mit pensio meint die Konsti-

27 Zum Datum s. die vorhergehende Anm.

28 Das Modell machte, wie spätere Belege für dieses Verfahren zeigen, Schule: CTh 15, 1, 26 (390) an Polemius, Prätoriumspräfekt von Italien und dem Illyricum (PLRE I, $710 \mathrm{~s}$. v. Polemius 5; Africa ist in seiner Amtsbezeichnung immer ausgespart, doch ist kein anderer Präfekt für Africa zu dieser Zeit bekannt) ermöglicht für den Fall, daß die eigenen Steuer- und Zolleinnahmen einer Stadt, die vectigalia, erschöpft sind, für Baumaßnahmen die Inanspruchnahme der vectigalia anderer Städte.

29 ... ex locis fundisve rei publicae annua praestatione confertur. so CTh 15, 1, 33 vom 5. Juli 395 an einen Vincentius, aller Wahrscheinlichkeit nach Vikar in Britannien oder Gallien (s. unten Anm. 32), wo bestätigt wird, daß die Städte zur Reparatur von Gebäuden (moenia) nicht mehr als den dritten Teil des canon in Anspruch nehmen dürfen; nach der Ausfertigung desselben Bescheids an den comes sacrarum largitionum (CTh 15, 1, 32) vom 21. Juni 395 ging es konkret um Arbeiten an einer Thermenheizung. Beinahe wörtlich dasselbe wiederholt als Replik auf eine Petition einen Monat später noch einmal CTh 5, 14, 35 vom 6. August an den Nachfolger des Eusebius, Hadrianus. Offenbar hatte also eine Stadt im Amtsbereich des Vincentius - erfolglos - beantragt, mehr als das ihr zustehende Drittel 
tution CTh 15, 1, 18 also den canon, den Pachtzins von städtischem Land, und in der Tat gestattet sie denn auch nur die Inanspruchnahme des canon anderer Städte. ${ }^{30}$

Der Finanzausgleich soll dann greifen, wenn, wie oben zitiert, „das Stadtvermögen im dritten Teil der Einkünfte" nicht ausreicht. Damit ist die Teilungsquote der städtischen Einnahmen, wie sie in Ex reditibus formuliert wurde, in CTh 15, 1, 18, dem „Finanzausgleichsgesetz“, schon vorausgesetzt: Die Stadt kann über die eigenen Einkünfte nur zu einem Drittel verfügen, den

am canon aufwenden zu dürfen. Die Petition wurde wiederholt, aber auch beim zweiten Versuch abgelehnt. Die Zugehörigkeit dieser drei Konstitutionen zu einem Vorgang ist nicht nur wegen ihres geringen Zeitabstandes wahrscheinlich, sondern angesichts der fast wörtlichen sprachlichen Bezüge nicht zu bezweifeln: vgl. insbesondere CTh 15, 1, 33 (praeter tertiam partem eius canonis, qui ex locis fundisque rei publicae quotannis conferri solet) und CTh 5, 14, 35 (... tertiam portionem eius canonis, qui ex locis fundisve rei publicae annua praestatione confertur). In CTh 15, 1, 33 wird auf Valentinians Quote übrigens mit den Worten sicut divi parentis nostri Valentiniani senioris deputavit auctoritas, „wie die Autorität Unseres seligen Ahnen, des älteren Valentinian bestimmt hat", verwiesen; damit ist ein Beleg gegeben, daß Valentinian tatsächlich als Urheber der Quotierungsregel gelten kann und Ex reditibus nicht bloß ein längst bestehendes Arrangement wiederholte.

30 Eine Wortuntersuchung zeigt, daß die Vokabel canon an dieser Stelle in der Tat keine andere als die prägnante Bedeutung „Pachtzins von städtischem Grundbesitz“ haben kann. Prinzipiell umfaßt die Bedeutung des Begriffs canon das ganze Wortfeld „Abgabe“: Als canon in der Bedeutung von "Steuer" wird grundsätzlich die annona urbis bezeichnet (vgl. diverse Konstitutionen der Titel 14, 15 + 16; außerdem CTh 14, 17, 14; 11, 14, 2; $12,6,24+13,5,27 ; 13,5,35$; NMaj $2 \$ 1$; weiterhin kann jede Art von Steuer so bezeichnet werden, allerdings dann immer mit einem qualifizierenden Zusatz: CTh 14, 6, 3: canon Tarracinensis; $10,19,4$ : canon metallicus; $7,6,2$ : canon vestium, $5,11,11$ : annonarii canonis vectigal; 1, 15, 10: canon annonae; 1, 15, 14: canon Africae, möglicherweise die annona urbis; 6 , 3, 4: canon senatorius, wohl die gleba senatus, $1,12,7$ : annonario ac superindicto canone; 16, 8, 29: canon de Synagogibus; NMaj 7 \$16: omnem canonem tam ad arcam praefecturae pertinentem quam sacris vel privatis largitionibus inferendum. In der überwiegenden Zahl der Fälle meint canon jedoch den „Pachtzins“; wenn der Begriff überdies wie hier ohne einen qualifizierenden Zusatz auftritt, hat er fast immer diese Bedeutung und wird ohne Erläuterung auch beinahe ausschließlich im Zusammenhang von Domänenland benutzt: CTh 5, 15, 17; 5, 13, $4 ; 11,16,13 ; 5,14,30 ; 5,14,34 ; 5,16,29 ; 12,9,3 ; 10,3,5 ; 11,7,19 ; 5,16,33 ; 5,12,2$; $11,5,2 ; 11,20,5 ;$ NTh $5,1 \rrbracket 1 ; 19 ; 5,3 \rrbracket 1 ; 26$; NMarc 3 . Einige wenige Ausnahmen bestätigen die Regel: In CTh 11, 16, 8 meint canon ohne Zusatz eine superindictio; 10, 20, 8 bezeichnet die Abgabe der Leinenweber als publicus canon; in 11, 1, 30 und 31 steht canon ohne Zusatz für die annona, unklar bleibt schließlich, welche Abgaben der Begriff in 1, 10, 1 und 9,42,16 umfaßt. Alle diese Bedeutungen treffen jedoch bei der hier diskutierten Konstitution CTh 15, 1, 18 nicht zu. Pensio dagegen ist ein untechnischer Begriff für alle Arten von Zahlungen und wird an dieser Stelle benutzt, um den Gegensatz zwischen „städtischen Einkünften aller Art" und der Beschränkung auf die Zinseinnahmen zu unterstre ichen. 
Rest kontrolliert der Staat, der ihn gegebenenfalls sogar anderen Städten überweisen kann. Waren die betroffenen Einkünfte in Ex reditibus nicht näher spezifiziert, zeigt CTh 15,1,18, daß dem dort festgehaltenen Aufteilungsschlüssel zumindest der canon unterlag. Die Quotierung betraf jedoch nicht nur die Pachteinnahmen. Im Jahr 431 oder 432 bestimmt die Konstitution CJ 4, 61, 13 an den jüngeren Nicomachus Flavianus, Prätoriumspräfekt von Italien, Afrika und Illyricum: ${ }^{31}$

Exceptis bis vectigalibus, quae ad sacrum patrimonium nostrum quocumque tempore pervenerunt, cetera rei publicae civitatum atque ordinum aestimatis dispendiis, quae pro publicis necessitatibus tolerare non desinunt, reserventur, cum duas portiones aerario nostro conferri prisca institutio disposuerat.

Mit Ausnahme derjenigen vectigalia, die zu einem gewissen Zeitpunkt an Unser kaiserliches patrimonium gelangt sind, sollen die anderen den geschätzten Aufwendungen der Städte und Stadträte, die sie für öffentliche Notwendigkeiten zu bestreiten nicht aufhören, vorbehalten bleiben, wobei eine althergebrachte Verfügung festgesetzt hat, daß zwei Anteile an Unseren Fiskus abgetreten werden.

Die prisca institutio, Valentinians Quotierungsregel, umfaßte also auch Einnahmen aus den vectigalia, den städtischen Steuern und Zöllen. Mit vectigalia und canon wurden demnach zumindest die regulären Einnahmequellen der Städte zwischen Stadt und Fiskus aufgeteilt. Hinsichtlich der übrigen Einkünfte wird man eine äquivalente Regelung annehmen dürfen.

Die Konstitution Ex reditibus vom September 374, CTh 14, 3, 7, kann jedoch nicht derjenige Erlaß gewesen sein, mit dem die Quotierungsregel eingeführt wurde. In der Tat wurde ja bereits im Januar 374 das „Finanzausgleichsgesetz" CTh 15, 1, 18 proponiert, in dem die Quotierung schon vorausgesetzt ist. CTh 14, 3, 7 muß daher wie CTh 15, 1, 18 ein Implementierungszeugnis der Reform sein, in dem das Verfahren wohl aus konkretem Anlaß dem Prokonsul von Africa bestätigt wurde; ein Hinweis darauf mag

31 Nicomachus Flavianus ist in diesem Amt durch CTh 6, 23, 3 und 11, 1, 36 in den Jahren 431 und 432 bezeugt, CJ 4, 61, 13 selbst hat seine Subskription im Zuge der Überlieferung verloren. Seeck, Regesten (wie Anm. 6), 125+358 meint, die Konstitution sei Fragment desselben Originals, von dem auch die Konstitution CTh 11, 1, 36 stammt, und datiert sie daher auf deren Datum, den 29. April 431. Die dafür vorgebrachten inhaltlichen Bezüge sind jedoch alles andere als zwingend: In CTh 11, 1, 36 geht es um die Grundsteuer, hier jedoch um städtische vectigalia. Die Datierung kann also nicht weiter eingegrenzt werden. 
sein, daß das Dokument explizit von „,billigenswerten Ausgaben“ (probabilia expensa) spricht - vielleicht gab es im Einzelfall Streit um die Verwendung der Gelder. Wurde CTh 15, 1, 18 aber bereits im Januar 374 proponiert, also im Spätjahr 373 ausgestellt, muß die Einführung des neuen Verfahrens in das Jahr 373 oder vielleicht schon 372 fallen.

Weiterhin zeigt die Parallelüberlieferung, daß Valentinians Quotierungsregel kein zeitlich oder örtlich begrenzter legislativer Akt war, sondern dauerhaft und im gesamten Reich Geltung besaß. Seine dauerhafte, zumindest bis zum Zeitpunkt der justinianischen Kodifikation währende Gültigkeit geht daraus hervor, daß die soeben zitierte Konstitution an Nicomachus Flavianus aus dem Jahre 431 als Fragment CJ 4, 61, 13 überliefert ist; da der „Codex Iustinianus“ (im Unterschied zum „Codex Theodosianus“) Konstitutionen obsoleten Inhalts nicht aufnahm, wäre sie andernfalls nicht an dieser Stelle überliefert worden. Was den Geltungsraum der Quotierungsregel anbetrifft, zeigt $C J 4$, 61, 13 ebenso wie die Erlasse über den „Finanzausgleich“, insbesondere CTh 15, 1, 18, daß die Quotierungsregel nicht nur, wie man aus dem Adressaten von Ex reditibus schließen könnte, in der Proconsularis, sondern in der gesamten Zentralpräfektur Gültigkeit besaß, und das oben bereits erwähnte Dossier von Erlassen aus dem Jahre 395 liefert den Nachweis, daß die Quotierungsregel auch in der westlichen Präfektur, in Spanien, Gallien und Britannien, also im gesamten Reichsteil Valentinians, Anwendung fand. ${ }^{32}$

32 Die Konstitution CTh 15, 1, 33 ist an einen gewissen Vincentius adressiert, enthält aber keinen Hinweis auf dessen Amt, da nur die Grußformel have Vincenti karissime nobis überliefert ist. Vincentius muß ein Amt in der westlichen Reichshälfte geführt haben, denn erstens sind die beiden anderen Dokumente des Dossiers, CTh 15, 1, 32 und 5, 14, 35, an zwei comites rerum privatarum des Honorius adressiert, und zweitens war im Jahr 397 ein gewisser Fl. Vincentius Präfekt von Gallien, den man gemeinhin für diesel be Person hält wie den Adressaten von CTh 15, 1, 33 (vgl. PLRE II, 1169 s. v. Vincentius 6). 395, als CTh 15, 1, 33 ausgestellt wurde, konnte Vincentius freilich noch nicht Präfekt gewesen sein, da 396 ein anderer in diesem Amt belegt ist (PLRE 1, 435f. s. v. Hilarius 11). Da es als äußerst unwahrscheinlich gelten kann, daß Vincentius noch zwei Jahre vor seiner Präfektur eine Statthalterschaft oder eine subalterne Position in der Finanzverwaltung z. B. als rationalis innehatte, die beiden Finanzcomitivae aber 395 anderweitig besetzt waren (CRP im Juli 395 ist Eulogius, CSL Eusebius oder schon Hadrianus: PLRE I, 294 s. v. Eulogius 2; $306 \mathrm{~s}$. v. Eusebius 32; $406 \mathrm{~s}$. v. Hadrianus 2), bleiben für die Identifizierung seines Amtes nur ein Prokonsulat oder ein Vikariat. Prokonsul von Afrika im Juli 395 ist ein gewisser Ennoius (PLRE I, 278 s. v. Ennoius), als Vikare sind Fabius Pasiphilus als vicarius Italiae und urbis bis zum 6. Januar 395 (PLRE I, 669 s. v. Pasiphilus 2), Hierius im März 395 (CTh 16, 2, 29) und später im Jahr Seranus (PLRE II, 992 s. v. Seranus) als vicarii Africae sowie Petronius als Vikar von Spanien seit dem 27. Juli 395 (PLRE II, 862 s. v. 
Einen Beweis, daß die Quotierungsregel auch im Ostteil des Reiches, der von Valentinians Bruder Valens regiert wurde, Geltung hatte, liefert zwar erst die Übernahme des Dossiers von 395 (CTh 15, 1, 32 als CJ 8, 11, 11, CTh 5, 14, 35 als CJ 11, 70,3) und der verlorenen Vorlage der oben genannten Konstitution CJ 4, 61, 13 in die justinianische Kodifikation. Es gibt allerdings keinen Grund zu bezweifeln, daß das von Anfang an auch im Osten der Fall war.

In den frühen 370er Jahren setzten Valentinian und Valens also gemeinsam einen bis mindestens ins sechste Jahrhundert hinein geltenden Schlüssel fest, nach dem die regulären Einkünfte aus den Einnahmequellen der Städte zwischen Gemeinde und Fiskus aufgeteilt werden sollten. ${ }^{33}$ Die Forschung stellt diese Maßnahme wie selbstverständlich in den Kontext der angeblichen (Re-)Konfiskation der städtischen Einkünfte durch Valentinian und Valens, die hier vorausgesetzt sei. Auch diese Deutung beruht jedoch auf der, wie sich zeigen wird, falschen Prämisse einer Globalkonfiskation. Wiederum fragt man sich nämlich, warum die vergleichsweise sehr dichte historiographische Überlieferung für die Regierungszeit Valentinians und Valens' sich über den Enteignungsakt, sollte er denn stattgefunden haben, ausschweigt. Nach Erklärung verlangt insbesondere auch der Mangel an entsprechendem dokumentarischem Quellenmaterial, zumal gerade die Fiskalpolitik der frühen Regierungsjahre 364 und 365 in den juristischen Quellen dicht bezeugt ist. ${ }^{34}$

Umgekehrt existiert jedoch eine Fülle positiver Quellenbelege bis in die Regierungszeit Justinians, die zeigen, daß die Städte auch nach 364 Eigen-

Petronius 1) belegt. Vincentius kann demnach nur vicarius Britanniarum oder quinque provinciarum gewesen sein, für die im Jahr 395 sonst niemand belegt ist.

33 Unklar ist, ob eine der beiden Parteien die Einkünfte verwaltete und einzog und dann der anderen den ihr zukommenden Anteil übergab, oder ob die Einkommensquellen selbst aufgeteilt wurden. Für ersteres ließen sich I.Ephesos 42; Lib. Or. 50, 5; CJ 4, 61, 13 und 11, 70, 6 sowie eine Reihe anderer Quellen anführen, für letzteres vielleicht die Existenz der Kategorie der fundi rei publicae im Domänenverband (s. dazu unten Anm. 35), die weit überwiegende Zahl der Quellen jedoch läßt keine Entscheidung zu. Vielleicht wurde das Problem auch individuell je nach Art der Einkünfte etc. gelöst. In jedem Fall ist die Quellenlage zu dünn, um mit Roland Delmaire (s. oben Anm. 4) annehmen zu wollen, das Verfahren sei irgendwann im späten vierten Jahrhundert geändert worden.

34 Zuweilen wird auf Valentinians CTh 10, 3, 2 (372), wo Dekurionen die Pacht von Gemeindeland untersagt wird, als Beleg dafür verwiesen, daß die Städte keine Kontrolle mehr über ihr Land besaßen. Dieses Verbot war in seinem Geltungsraum jedoch sicherlich situativ begrenzt, denn anderswo sind Kurialen ganz selbstverständlich als Pächter belegt: z. B. CJ 11, 59, 1; 5; CTh 10,3, 4; 5; 11, 24, $6 \$ 5 ; 15,1,41$. Tatsächlich dürfte es in CTh 10, 3, 2 lediglich um das auch sonst belegte Verbot gehen, daß die Kurien sich in die lokale Domänenverwaltung einmischten: vgl. z. B. CJ 11, 73, 1 in einem Zusatz zu seiner Vorlage und bereits Dig. 50, 8, 2 (Ulpian). 
tumsrechte an den fundi rei publicae und anderen Einkommensquellen ausübten. So halten zahlreiche Gesetzestexte einen Eigentumstitel der Städte fest, wenn sie beispielsweise Ländereien als praedia quae ad ius civile pertinent bezeichnen. ${ }^{35}$ Wenn man nicht Kategorien wie den Konservatismus der römischen Verwaltung oder überholte Vorstellungen von konzeptionellen Aufweichungen oder terminologischen Unschärfen im spätrömischen Recht bemühen möchte, ist es nicht leicht zu erklären, warum noch mindestens ein Jahrhundert nach der angeblich endgültigen Enteignung des städtischen Grundbesitzes eine (dann materiell falsche) Nomenklatur fortgeführt worden sein sollte. Die Evidenz ist dabei im übrigen keineswegs auf juristische Quellen beschränkt: In der Debatte bislang übersehen wurde eine spätrömische Inschrift aus Thessalien, die den Grenzverlauf zwischen einem privaten Großgrundbesitz und $\tau \grave{\alpha} \delta \eta \mu o ́ \sigma 1 \alpha$, städtischem Land, beschreibt, zugleich aber $\tau \grave{\alpha} \delta \varepsilon \sigma \pi 0 \tau 1 \kappa \alpha ́$, kaiserliches Land, von diesen beiden separat ausweist ${ }^{36}$.

35 So NTh 23 (443); vgl. außerdem z.B. CTh 15, 1, 42 (404; iura civium auf innerstädtische ergasteria); NTh 17, $2 \ 5$ (444: ad ius publicum pertinentes); NMarc 3 (451: praedia iuris civilis); CJ 11, 70, 6 (480: canonis civilis reditus ad suam patriam pertinentis). Kaiser Zeno verbot in CJ 8,12, 1 den discussores städtischer Bauprojekte, „die aus städtischen Einkünften (civiles reditus) oder durch freiwillige Munifizenz errichtet wurden oder werden", die Erhebung einer Sportel - die civiles reditus dürften hier ebenfalls Einnahmen aus städtischen Einkommensquellen anstelle von staatlich zugewiesenen Geldern meinen, denn dann läge hier eine Konstitution gegen die Selbstbereicherung an Staatsmitteln vor. Dieses Thema wird freilich mit keinem Wort erwähnt. Die Tatsache, daß bis in die justinianischen Novellen hinein im Domänenverband die separate Kategorie der fundi rei publicae existiert, impliziert für sich alleine keinen Eigentumstitel der Städte, denn auch die fundi iuris templorum werden zumindest bis ins spätere 5. Jahrhundert hinein als separate Kategorie geführt, obwohl sie nach allgemeiner Auffassung ja tatsächlich konfisziert wurden. Allerdings gewinnt die Tatsache vor dem Hintergrund, daß eine Konfiskation im juristisch prägnanten Sinne einer Enteignung des Gemeindebesitzes nicht belegt ist, möglicherweise doch eine gewisse Signifikanz: Vielleicht weist die Nomenklatur im Domänenverband darauf hin, daß diese Güter vom Fiskus eben nur verwaltet, nicht aber als Eigentum besessen wurden. J. H.W.G. Liebeschuetz, Civic finance in the Byzantine period, BZ 89, 1996, 389407, hier: 389-393 deutet die genannten und Quellen des fünften und sechsten Jahrhunderts so, daß es sich dabei um Gelder handele, die zwar vom Staat erhoben, dann aber den Städten für bestimmte Zwecke wieder zurücküberwiesen worden seien (und insofern mit Recht z. B. als civiles reditus bezeichnet worden sein könnten). Selbst wenn das der Fall wäre, scheitert diese Interpretation an den gleich noch vorzustellenden Quellen, die zweifelsfrei die Erhebung von Einkünften unter städtischer von der unter staatlicher Regie abgrenzen.

36 F. Gschnitzer, Eine spätrömische Grenzinschrift aus Thessalien, Demetrias 5, 1987, 339. 351 mit Taf. XXXIV-XXXV (= ders., Kleine Schriften zum griechischen und römischen 
Auch in der administrativen Praxis bestand demnach weiterhin eine klare Trennung der beiden Güterkategorien.

Das offenkundig also fortbestehende Eigentumsrecht der Gemeinden an ihren Besitzungen war indessen kein bloß nominelles. Zahlreiche Quellen belegen nämlich auch die faktische Ausübung von Besitzrechten durch die Städte. Nach einer Reihe von literarischen und juristischen Quellen vom späten vierten bis ins sechste Jahrhundert konnten die Städte Liegenschaften und andere Güter als Legate und Stiftungen empfangen ${ }^{37}$ und als Käufer und Verkäufer ihrer Güter agieren; in einer Konstitution des Jahres 469 heißt es beispielsweise: „Wenn irgend etwas als Erbschaft, Legat, Fideikommiß oder Stiftung, sei es ein Haus, annonae civiles, irgendwelche Gebäude oder Sklaven ... in das Eigentum irgendeiner Stadt gelangen sollte oder schon gelangt ist, soll es den Gemeinden freistehen, darüber Verträge zu ihrem Vorteil abzuschlieBen, damit der daraus erzielte Höchstpreis der Renovierung und Wiederherstellung öffentlicher Gebäude zukomme“. ${ }^{38}$ In den 380er-Jahren erwähnt Libanios einmal, daß die Stadt Antiocheia über Grundbesitz verfüge, den sie an Pächter ihrer Wahl vergeben könne, ${ }^{39}$ und nach dem Säulenkrawall von 387 rühmt er Kaiser Theodosius dafür, daß dieser durch die Rückerstattung der zur Strafe konfiszierten städtischen Ländereien wahrhaft kaiserliche clementia bewiesen habe. ${ }^{40}$ Hier handelte es sich mit Sicherheit weder um ein

Altertum, Bd. II, Stuttgart 2003, 455-469) mit ausführlichem Kommentar. Für den Hinweis auf diese Inschrift danke ich Hans-Ulrich Wiemer.

37 CIL XIV 2934 = ILS 8375 (385); Lib. Or. 50, 5. CJ 11, 32, 3 (469); 1, 11, 9 (nach 472); 1, 4, 26 (530); NJust 38 (535); 160 (undatiert). Andere Einkommensquellen sind: die Güter von Dekurionen, die die Kurienmitgliedschaft aufgeben (NJust 149); Güter eines Dekurionen, der eine Sklavin zur Konkubine hat (CTh 12,1, 6); stra fweise konfiszierter Besitz korrupter Beamten (CJ 8, 12,1).

38 CJ 11, 32, 3 (469): Si qua bereditatis vel legati aut fideicommissi aut donationis titulo domus aut annonae civiles aut quaelibet aedificia vel mancipia ad ius ... cuiuslibet civitatis pervenerunt sive pervenerint, super bis licebit civitatibus venditionis pro suo commodo inire contractum, ut summa pretii exinde collecta ad renovanda sive restauranda publica moenia dispensata proficiat. Vgl. auch CJ 11, 70, 2; NTh $23 \$ 1$ (443); 160 (undatiert).

39 Lib. Or. 52, 33.

40 Lib. Or. 20, 7. Chastagnol, AARC 6, 1986 (wie Anm. 4), 102 behauptet, diese LibaniosStellen würden durch Or. 48, 3 entkräftet, wo der Verlust städtischen Landbesitzes an den Staat unzweifelhaft impliziert sei. Dort steht allerdings nur, daß die Zahl der Dekurionen rückläufig sei und ihre Äcker jetzt von anderen bebaut würden. Auch Delmaire, Largesses sacrées (wie Anm. 4), 654, für den die Städte, wie oben gezeigt, erst im Jahre 431 Eigentum an Liegenschaften hatten, bestreitet die Signifikanz von Or. 20, 7, weil es dort nur um die Restitution städtischen Territoriums gehe, nicht um die Rückgabe städtischer Domänen. Allerdings dürfte die Wiederherstellung des Territoriums bereits in der 
bloß nominelles Eigentum noch um eine Verwaltung der Güter für den Fiskus, denn nach Libanios bezog die Stadt aus den Verpachtungen selbst Einkünfte. Und die Restitution ihrer Güter nach den Krawallen wäre wohl kaum als herausragender Beweis kaiserlicher Milde für die Stadt gepriesen worden, wenn deren Erträge in die Kasse des Fiskus geflossen wären. Eine faktische Verfügungsgewalt der Städte über die Einkünfte ihrer Ländereien bezeugt auch eine Konstitution Zenos (CJ 11, 70, 6), die im Jahre 480 der Stadt Nikaia das ius exactionis, also die eigenverantwortliche Erhebung des Pachtzinses von einigen Gütern, die ihr einige Zeit zuvor genommen worden waren, restituiert. Eigentum und Nutzung der Güter lagen hier also gleichermaßen bei der Stadt.

Jeglichen Zweifel an der Verfügungsgewalt der Städte über ihre Einkünfte räumen schließlich einige Quellen aus, in denen die Rechte von Fiskus und Stadt an den munizipalen Einkommensquellen gegeneinander abgegrenzt werden. In der Konstitution CTh 5, 14, 35 aus dem oben erwähnten Dossier aus dem Jahr 395 werden die Einnahmen aus dem canon, die aus den loci fundique rei publicae erzielt werden, explizit von den vectigalia publica abgesetzt, „die schon immer vollständig die Ausgaben Unseres Fiskus deckten"; von ihnen „etwas unter dem Titel der Städte abzuzweigen“, sei unzulässig. ${ }^{41}$ Anders als gewisse vectigalia floß besagter canon, so läßt sich dieser Anordnung im Umkehrschluß entnehmen, also nicht dem Fiskus zu, sondern in städtische Kassen, ja offenbar galt es sogar zu verhindern, daß diese mehr Einkünfte usurpierten als ihnen zustand.

Dieser Fall einer expliziten Gegenüberstellung staatlich und städtisch verwalteter Gelder steht nicht alleine: In der oben bereits genannten Konstitution CJ 4, 61, 13 an Nicomachus Flavianus sah sich Valentinian III. im Jahr 431 genötigt, den von Valentinian I. und Valens festgesetzten Aufteilungsschlüssel in bezug auf die vectigalia zu wiederholen. Oben wurde die Passage

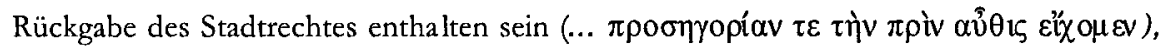
während nun die Rückgabe von Vermögenswerten (darunter auch Gelder für Spiele und die annona) berichtet wird; überdies scheint die Formulierung $\tau \grave{\eta} v$ ai் keren Besitz zu implizieren als lediglich den eines Territoriums. Ebensowenig aussagekräftig sind für Delmaire a. a. O. die anderen Libanios-Stellen, da sie nur agonothetische Güter beträfen, also für die Frage insignifikant seien. Abgesehen von der Frage, warum die agonothetischen Güter von den anderen städtischen Gütern zu trennen sein sollten, geht es in Or. 31, 16-20 zwar durchaus auch, aber keineswegs ausschließlich um agonothetisches Land, und in den anderen Quellen ist von dieser Einschränkung überhaupt keine Rede.

41 De vectigalibus itaque publicis, quae semper ex integro nostri aerarii conferebant expensas, nibil ommino decerpi nomine civitatum permittimus. 
zitiert, in der diejenigen vectigalia, die an den Fiskus gehen, ausdrücklich von den städtischen abgesetzt werden, die im Verhältnis 2:1 zwischen Fiskus und Stadt aufgeteilt wurden. Dann heißt es weiter:

\begin{abstract}
Atque banc tertiam iubemus adeo in dicione urbium municipumque consistere, ut proprii compendii curam non in alieno potius quam in suo arbitrio noverint constitutam. designatae igitur consortium portionis eatenus iuri ordinum civitatumque obnoxium maneat, ut etiam locandi quanti sua interest licentiam sibi noverint contributam.
\end{abstract}

Jenes Drittel soll so weitgehend der Verfügungsgewalt der Städte und Kurialen unterstehen, daß sie wissen, daß die Verantwortung für ihren eigenen Vorteil eher in ihrer eigenen Entscheidungsgewalt als in derjenigen eines anderen gründet. Der Besitz $^{42}$ an dem festgesetzten Drittel bleibe insoweit dem Rechtsanspruch der Kurien und Städte unterworfen, daß sie wissen, daß ihnen auch das Recht der Verpachtung zu dem ihnen angelegentlichen Zinssatz überlassen bleibt.

Die Städte haben für ihren Anteil an den städtischen Einkünften also auch hier ein eigenständiges Verfügungsrecht, das ausdrücklich von dem des Fiskus abgesetzt wird.

Eine explizite Trennung der durch die Gemeinde eingezogenen städtischen Einkünfte von den dem Fiskus zufließenden findet sich auch später noch. Auf Bitten der Stadt Herakleia Salbakes ordnete Kaiser Theodosius II. in der Konstitution NTh 23, 1 aus dem Jahr $443^{43}$ an, unrechtmäßig in Privatbesitz übergegangene Liegenschaften in ihren ursprünglichen Status, also in den Besitz der Stadt, zurückzuführen; ausgenommen davon soll lediglich Besitztum sein, von dem urkundlich bewiesen werden könne, daß es durch die Domänenverwaltung in kaiserlichem Auftrag veräußert wurde. ${ }^{44}$ Die Beispiele lassen sich fortsetzen: Zwei Jahre später, 445, befahl Valentinian III., den Hafenzoll der numidischen Städte Rusicade und Chullu in einer

42 Die Vokabel consortium kann im Sinne eines ,gemeinschaftlichen Besitzes“ (CTh 11, 13, 1; vgl. auch ThlL IV, $488 \mathrm{~s}$. v. consortium I) benutzt werden; ihre Wahl ist hier wohl von der Vorstellung eines „Gemeindebesitzes“ bestimmt gewesen.

$43 \mathrm{Zu}$ Datierung und Ausstellungsort vgl. Ch. Roueché, Theodosius, the Cities, and the Date of the Church History of Sozomen, JThS n. s. 37, 1986, 130-132.

44 Quae ... a procuratore divinae domus vel a viro inlustri comite rerum privatarum iussu nostrae clementiae ... distractae sunt. Die Konstitution sieht außerdem den Sonderfall vor, daß Liegenschaften „auf einmütigen Beschluß der Städte hin“ (communi consensu civitatum) veräußert wurden. 
Quote von 2:3 zwischen Stadt und sacrae largitiones aufzuteilen. ${ }^{45}$ Eine Novelle Marcians im Jahre 451 befiehlt den Pächtern städtischer Güter, die, mit welchem Recht auch immer, keinen Pachtzins gezahlt hatten, diesen von nun an der Stadt zu leisten. Anders liege der Fall jedoch dann, wenn „... die städtischen Güter den Pachtzins der res privata ... schulden [...] - dann sollen sie nicht dieser pragmatischen Sanktion unterliegen, sondern wie gewohnt der res privata den Pachtzins ... zahlen. "46 Noch in der zweiten Hälfte des fünften Jahrhunderts halten die Rechtstexte also eine klare Differenzierung zwischen

45 NVal 13, 1. Daß die Quote nicht der von 372 (1:2) entspricht, mag sich daraus erklären, daß diese das Gesamtaufkommen der städtischen Einkünfte betraf, während die daran beteiligten Einzelposten je nach Situation unterschiedlich aufgeteilt werden konnten. Man muß hier deshalb nicht mit Delmaire, Largesses sacrées (wie Anm. 4), 279f., die Existenz eines gemischt städtisch-staatlichen Zolls annehmen. Die Quellenlage für städtische Zölle in der Spätantike ist ansonsten spärlich: Justinians Edikt 13, 15f, legt zwar die Verwendung eines alexandrinischen Zolles namens exagogion $u$. a. für städtische Zwecke, z. B. Bäder, fest; daraus geht aber nicht hervor, ob das exagogion in der Spätantike ein von der Stadt erhobener oder ein staatlicher Zoll war: vgl. dazu J. Karayannopulos, Das Finanzwesen des frühbyzantinischen Staates, München 1958, 152f. Auch die Zollinschriften der Epoche sind für die Frage nicht hilfreich: I.Mylasa 611 (= CIL III 7151f.) bewahrt eine kaiserliche Antwort auf eine Petition in Sachen Hafenzöllen, die, wie es dort heißt, der Stadt Mylasa ebenso wie dem Fiskus Nutzen bringen solle (Z. 2); da der Rest des Textes jedoch sehr fragmentarisch ist, ist ihm nichts darüber zu entnehmen, ob es sich um Reichs- oder Stadtzölle handelte, wer jeweils das Eigentum daran hatte, wer sie verwaltete und wie sie ggf. zwischen Fiskus und Stadt aufgeteilt wurden (vgl. dazu zuletzt Merola, AARC 13, 2001 (wie Anm. 4), 277-283 und dies., Autonomia locale (wie Anm. 4), 135-137). Eine Inschrift des späten sechsten Jahrhunderts aus Caralis betraf ebenfalls Zölle, die von ihrem Herausgeber J. Durliat, Taxe sur l'entrée de marchandises dans la cité de Caralis (Cagliari) à l'époque byzantine 582-602, DOP 36, 1982, 1-14 als städtisch gedeutet wurden, weil dort auch von gesta municipalia die Rede ist. Der Zustand des Dokument ist freilich so fragmentarisch, daß die Frage, ob hier ein städtischer oder ein staatlicher Zoll erhoben wurde, kaum zu klären ist. Ebenso unergiebig sind die Zollinschriften aus Anazarba, Beirut und Caesarea Maritima: vgl. die Literaturangaben bei Liebeschuetz, Decline (wie Anm. 2), 177 Anm. 45; Quellenüberblick bei Delmaire, Largesses sacrées (wie Anm. 4), 276-278; Merola, Autonomia locale (wie Anm. 4), 134-139. Die Papyri tragen nichts zu der Frage nach einer eigenständigen städtischen Zoll- und Steuererhebung bei, auch die Steuerlisten von Antaiopolis und Aphrodito betreffen nur die Verwendung staatlicher Steuern für staatliche Zwecke: Vgl. dazu zuletzt Liebeschuetz, BZ 89, 1996 (wie Anm. 35), 393-395 mit der Schlußfolgerung, da hier keine städtischen Belange (Bäder etc.) au fgelistet seien, müßten diese aus separaten und dann städtischen Einkünften finanziert worden sein. Dieser Schluß ist nicht zwingend.

46 NMarc $3 \rrbracket 1 \mathrm{f}=\mathrm{CJ} 11,70,5: \ldots$ si quae tamen possessiones iuris civilis canonem privatis largitionibus ... praebent $[. .$.$] , ad banc pragmaticam sanctionem iussionem non pertinebunt, sed privato aerario$ canonem ... inferre ex more debebunt. 
munizipalen Abgabentiteln fest, die dem Fiskus zufließen, und solchen, die den Gemeinden zugute kommen; diese Aufteilung von $\pi 0 \lambda \iota \tau 1 \kappa \grave{\alpha} \chi \rho \eta \mu \alpha \tau \alpha$ zwischen Fiskus und Stadt ist schließlich noch im Jahre 496 durch Anastasius' Erlaß CJ 10, 16, 13, 3 belegt. ${ }^{47}$

Aus diesem Quellenüberblick ergeben sich drei Feststellungen: Erstens zeigt eine Reihe von Quellen vom späten vierten Jahrhundert bis in die Regierungszeit Justinians, daß die Gemeinden auch nach der vermeintlichen (erneuten) Konfiskation unter Valentinian und Valens Eigentum an städtischen Liegenschaften und Steuer- und Zolleinnahmen hatten. Zweitens kann kein Zweifel bestehen, daß dieses Eigentum nicht ein bloß formales war, sondern eine reale Verfügungsgewalt über mindestens einen Teil davon mit sich brachte. Gleichwohl führen die zuletzt genannten Quellen drittens ebenfalls vor, daß es auch städtische Einkünfte gab, die in der Verwaltung des Fiskus lagen und deren Einnahmen er einzog. Wie ist dieser paradoxe Quellenbefund zu deuten? Die Forschung kommt, wie eingangs referiert, $z \mathfrak{u}$ folgender Lösung: Die Städte seien von Valentinian und Valens zwar (wieder) enteignet worden, doch sei man bald davon abgekommen, die Einkünfte auch direkt durch den Fiskus verwalten zu lassen. Denn bei jeder Ausgabe mußten nun die Städte bei den Finanzbehörden vorstellig werden, was langwierig und hauptsächlich der Korruption unter den beteiligten Beamten förderlich gewesen sei. Den Städten sei daher ein Teil der Einkünfte zur eigenständigen Verwaltung und Abgabenerhebung überlassen worden. Dieser Anteil sei zunächst variabel bestimmt, dann aber durch die Quotierungsregel Valentinians Anfang der 370er Jahre pauschal auf ein Drittel festgesetzt worden (wobei das Eigentum an den Abgabentiteln beim Fiskus verblieben sei).

Befriedigen kann auch diese Interpretation nicht. Sie vermag zwar eine Erklärung zu bieten, warum nach der Quellenlage des späteren vierten und fünften Jahrhunderts Städte und Fiskus gleichermaßen über städtische Einkünfte verfügen konnten. Sie kann aber weder die Zeugnisse integrieren, nach denen die Städte auch nach der Reform der 370er Jahre Eigentumsrechte ausübten, noch irgendeinen positiven Beleg für die Konfiskation Mitte der 360er Jahre namhaft machen. Tatsächlich beruft sich die Forschung dafür auf eine einzige Quelle, die die Konfiskation unter Valentinian und Valens zwar wiederum nicht direkt belegt, aus der man aber sowohl die Enteignung sicher

47 Proc. H. A. 26, 6 wirft Justinian vor, die Ausgaben, die Privatleute für die Stadt und das

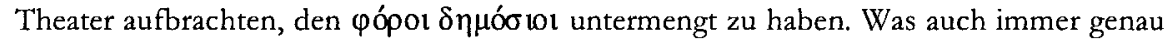
damit gemeint ist, läßt sich daraus doch gewiß keine generelle Konfiskation unter Justinian erschließen, zumal andere Quellen aus seiner Regierungszeit wie gezeigt das Gegenteil belegen. 
erschließen zu können glaubt als auch das beschriebene Arrangement einer partiell eigenständigen Verwaltung der ehemals munizipalen Einkünfte durch die Gemeinden, nun jedoch im Namen des Fiskus. Im folgenden Abschnitt wird indessen nachgewiesen werden, daß besagte Quelle nichts über eine globale Konfiskation städtischen Grundeigentums und auch nichts über seine spätere Verwaltung aussagt, sondern in einem ganz anderen Sachzusammenhang steht. Auf dieser Grundlage wird es möglich sein, auch für die Quotierungsregel der $370 \mathrm{er} \mathrm{Jahre} \mathrm{eine} \mathrm{schlüssigere} \mathrm{Interpretation} \mathrm{zu} \mathrm{finden.}$

\section{Die Inschrift von Ephesos (I.Ephesos 42)}

Seit dem Jahr 1905 ist eine lateinische Inschrift aus der Metropole der Provinz Asia, Ephesos, bekannt, die einen Erlaß Kaiser Valens' an den proconsul Asiae Eutropius überliefert. ${ }^{48}$ Valens' Epistel ist ohne Subskription aufgezeichnet worden und kann deshalb nur anhand der Karriere ihres Adressaten Eutropius, besser bekannt als Verfasser eines Breviariums zur römischen Geschichte, datiert werden; für sein Prokonsulat in Asia und die Abfassungszeit der Epistel kommen demnach nur die Jahre 369 bis spätestens 372 in Frage. ${ }^{49}$

48 I.Ephesos 42. Die heute (trotz einiger Fehler im Text) verbindliche Edition im Kölner Corpus der Inschriften von Ephesos stammt von Hermann Wankel; immer noch nützlich auch für Fragen der Textkonstitution sind die Anmerkungen von R. Heberdey, Zum Erlaß des Kaisers Valens an Eutropius, JÖAI 9, 1906, 182-192, der den Kommentar der ersten Textedition von A. Schulten, ebd. 40-70 in bezug auf mehrere Irrtümer und Fehlschlüsse korrigiert. Keinen Erkenntnisgewinn bringt der (mit stillschweigend vorgenommenen Emendationen versehene) Text bei Chastagnol, AARC 6, 1986 (wie Anm. 4); ebenso wenig zuverlässig auch der Text in FIRA I 108.

49 Über die Identifizierung des Adressaten mit dem Historiker Eutrop herrscht weitestgehend Einigkeit; vgl. B. Malcus, Die Prokonsuln von Asien von Diokletian bis Theodosius, Stockholm 1967, 11-113; PLRE I, 317 s. v. Eutropius 2; G. Bonamente, La biografia di Eutropio „lo storico", AFLM 10, 1977, 179-210; H. W. Bird, The Breviarium of Eutropius, Liverpool 1992, vii-xliv; P. L. Schmidt in: R. Herzog (Hg.), Restauration und Erneuerung: die lateinische Literatur von 284 bis 374 n.Chr., München 1989, 202f. mit weiterer Literatur; dagegen aber R. von Haehling, Die Religionszugehörigkeit der hohen Amtsträger des Römischen Reiches seit Constantins I. Alleinherrschaft bis zum Ende der Theodosianischen Dynastie, Bonn 1978, 211-237. In der Regel werden nur die Jahre 370/1 für das Prokonsulat angesetzt, hier dagegen die breitestmögliche Amtszeit: Eutrop war 369 noch magister memoriae, wurde aber noch im selben Jahr von seinem Rivalen Festus beerbt. Da sonst kein proconsul Asiae in jener Zeit bekannt ist, könnte Eutrop bereits 369 das Amt übernommen haben, in dem er durch Amm. 29, 1, 36 im Zusammen- 
Der Erlaß beginnt ${ }^{50}$ mit dem Referat einer relatio des Eutrop, aus der sich die Vorgeschichte der von Valens getroffenen Entscheidung rekonstruieren läßt: Kaiser Valens hatte, so geht aus dem ersten Abschnitt (Z. 2-4) hervor, gewissen Städten die Einkünfte von fundi rei publicae zu Teilen zur Verfügung gestellt, damit sie daraus die Reparatur von Mauern oder Gebäuden finanzieren konnten, um sie ,aus dem häßlichen Schmutz jüngst erfolgten Schadens“ wiedererstehen zu lassen. ${ }^{51}$ Die Güter wurden, wie ein zweiter Abschnitt (Z. 4-8) festhält, in diesem frühen Stadium durch actores der res privatae ${ }^{52}$ verwal-

hang der Antiochenischen Magieprozesse 370/1 belegt ist. Sein Nachfolger im Prokonsulat war (bis spätestens 378) wieder Festus, dessen Amtsantritt allerdings nur ungefähr zu bestimmen ist (vgl. die Belege bei PLRE I, 334 s. v. Festus 3; Malcus, Prokonsuln, 114-116 sowie vgl. B. Baldwin, Festus the Historian, Historia 27, 1978, 197-217, hier: 197-207; P. L. Schmidt in: Herzog, Restauration, 207f. mit weiterer Literatur): Er ist ebenfalls Adressat einer gemeinsam mit I.Ephesos 42 aufgezeichneten Inschrift, I.Ephesos 43. Damit ist ein - weil der zeitliche Abstand der beiden Dokumente nicht zu bestimmen ist, ungenauer - Terminus post quem für Festus' Amtsübernahme gegeben; das Jahr 372 paßt als grobes Datum für die Amtsübernahme auch insofern gut, als Festus sich im Anschluß an die Antiochenischen Magieprozesse 370/1 in der Verfolgung angeblicher Oppositioneller auszeichnete (Quellen s. PLRE ebd.). Für Eutrops Amtszeit und die Datierung von I.Ephesos kommt also die Zeitspanne 369 bis etwa 372 in Frage.

50 Eine bloße Übersetzung des Dokumentes trägt kaum zum Verständnis seiner komplizierten Struktur bei; stattdessen wird im folgenden eine chronologische Rekonstruktion des darin festgehaltenen Vorgangs gegeben.

51 Ein konkretes Ereignis als Hintergrund der Reparaturmaßnahmen läßt sich nicht benennen: Die zwischen 358 und 368 mehrfach bezeugten Erdbeben traten größtenteils im bithynischen Raum, vereinzelt auch in Zentralkleinasien und Palästina auf, nicht aber in der Provinz Asia; auch das Beben und der Tsunami von 365 haben dort offenbar keine Schäden angerichtet: vgl. die Zusammenstellung der Belege bei N. Lenski, Failure of Empire: Valens and the Roman State in the Fourth Century A.D., Berkeley 2002, 386388; zum Tsunami 365 vgl. aus der intensiven Diskussion der letzten Jahrzehnte J. Bousquet/F. Jacques, Le raz du marée du 21 Juillet 365 . Du cataclysme local à la catastrophe cosmique, MEFRA 96, 1984, 423-461; C. Lepelley, L'Afrique du Nord et le prétendu séisme universel de 21 juillet 365, ebd. 463-491; neuerdings stellt G. Waldherr, Die Geburt der kosmischen Katastrophe. Das seismische Großereignis am 21. Juli 365 n.Chr., OTerr 3, 1997, 169-201, das Ausmaß der Katastrophe generell in Frage. Formulierungen wie die der Inschrift scheinen im übrigen keineswegs unbedingt auf ein konkretes Katastrophenereignis anzuspielen, da spätrömische Baugesetze sich gelegentlich solcher rhetorischen Phrasen befleißigen, ohne daß irgendwelche Hinweise auf einen Unglücksfall entsprechenden Ausmaßes existierten: So Valentinians CTh 15, 1, 11: deformibus ruinis, während in den etwa zeitgleichen 15, 1, 15 und 16 schlicht von Altersschwäche die Rede ist; vgl. auch 15, 1, 14 (390, Unteritalien).

52 Actores rei privatae scheinen - wenngleich auch in einer für uns nicht immer ganz klar von den conductores zu scheidenden Weise - mit der Verwaltung von Domänenland, vielleicht 
tet, die die Einkünfte daraus auf Anfrage an die Städte weitedeiteten. Gegen dieses Verfahren hatte sich eine Gesandtschaft der Stadt Ephesos an den Kaiser gewandt, von der im dritten Abschnitt (Z. 8-12) berichtet wird. Nachdem der Kaiser, so heißt es dort, die vorgetragene Schilderung des Sachverhalts in einer eigenen Untersuchung hatte verifizieren lassen, gestattete er der Stadt Ephesos, hundert inga einschließlich eines schon früher übertragenen Gutes namens Leuce in ihre Verwaltung zu übernehmen. Durch diesen „Testlauf" wollte der Kaiser erproben, ob die Reparaturmaßnahmen unter diesen Umständen besser vorankämen; wenn das der Fall sein sollte, könne das Modell auch auf alle anderen Städte der Provinz angewandt werden.

Dieses Arrangement scheint einige Jahre vor dem Eingreifen Eutrops getroffen worden zu sein; nun, im unmittelbaren Vorfeld des Erlasses, nahm dieser sich der Sache an und schlug dem Kaiser in der oben referierten relatio vor, das Modell der Verwaltung durch die Städte für alle betroffenen fundi rei publicae in der Provinz Asia verbindlich zu machen. Zur Begründung brachte der Prokonsul folgendes vor (Abschnitt II):

Verum non integram grat [iam con]cessi ad urbes singulas beneficii ${ }^{5}[$ perv]enire, siquidem, $<d u m>$ pro partibus praestitis reditus civitatibus potius q[ua]m ipsi cum reditibus fundi fuerint restitu[end]i et ministrandi, idem reditus ab acto[ri]bus ${ }^{6}[\mathrm{pr}]$ ibatae rei nostrae et diu miserabiliterque poscantur et vix aegr $\{a\}$ eque tribuantur adque id quod amplius e $[x$ i]sdem fundis super statutum canonem ${ }^{7}$ colliga $\{n\}$ tur et isdem civitatibus pereat eorundemqu$\{a\}$ e actorum fraudibus devoratum nibil tamen aerario nostro adiciat augmenti possitque ${ }^{8}$ a curialibus vel excultione maiore vel propensiore diligentia nonnullus praestitionis cumulus ad gratiam concessionis acedere.

Den einzelnen Städten fließt freilich nicht die ungeschmälerte Gunst der gewährten Wohltat zu, da ja, solange den Städten eher ein Anteil an den Einkünften zugestanden ist, als daß die Güter selbst mit ihren Einkünften zur Verwaltung zurückgegeben werden, besagte Einkünfte von den actores Unserer res privata lange und umständlich eingefordert werden müssen und sie in geringem Maße und zögerlich zugeteilt werden. Und das, was über den festgesetzten Zins hinaus von besagten Gütern gesammelt wird, ist für besagte Städte ebenso verloren wie es auch Unserem Fiskus keinen Gewinnzuwachs bringt, weil es von den Betrügereien besagter actores aufgezehrt wird. Von Seiten der Kurialen kann sowohl durch bessere Bewirtschaftung als auch durch eifrigere Sorgfalt ein nicht geringer Zuwachs der Schenkung zu dem huldvoll Zugestandenen eintreten.

dem in staatlicher Regie bewirtschafteten, tätig gewesen zu sein: Jones, Later Roman Empire (wie Anm. 3), 414 und 788; Delmaire, Largesses sacrées (wie Anm. 4), 679f. 
Solange die Güter durch den Fiskus verwaltet würden, müßten, so argumentierte Eutrop also, die Städte für jede Ausgabe bei den actores der res privata vorstellig werden, was umständlich sei und hauptsächlich deren Selbstbereicherung zustatten komme. Nähmen dagegen die Kurialen die Verwaltung selbst in die Hand, könne man durch bessere Bewirtschaftung sogar noch einen Gewinnzuwachs erzielen.

Valens ließ sich von diesen Argumenten offenkundig überzeugen, denn nun, im eigentlich dispositiven Teil der Konstitution ab dem vierten Abschnitt (Z. 12-19), wird Eutrop angewiesen (Z. 17-19):

Arbitrio tuo per curias singulas omni ingatione dispersa, retracto eo redituum modo, quem unicuique civitatum propria largitione concen[simus], ${ }^{18}[$ r] $]$ liquam summam per officium tuum rei privatae nostrae inferre festines, ut et omnem usu ram diligentia $\{m\}$ avidis eripiamus actoribus et, siquid extrinsi[cus] 19 [lucri] est, cedat rationibus civitatum.

Nach der Verteilung des Gesamtbestandes an iuga auf die einzelnen Kurien nach Deinem Ermessen sollst Du, nachdem die Einkünfte in derjenigen Höhe, die Wir einer jeden Stadt in der Uns eigenen Freigebigkeit zugestanden haben, abgezogen wurden, unverzüglich die Restsumme durch Deine Behörde an Unsere res privata bringen lassen, damit wir sowohl durch Sorgfalt den begehrlichen actores jeden Eigennutz nehmen als auch, wenn es darüber hinaus irgendeinen Gewinn gibt, er den Finanzen der Städte zukomme.

Eutrop soll also die betroffenen, in Z. 14-16 ihrem Umfang nach genau bezifferten Güter nach eigenem Ermessen auf alle Städte seiner Provinz verteilen. Diese sollen fortan einen individuell festgesetzten Anteil ihrer Einkünfte einbehalten dürfen, den Rest aber an den Fiskus abführen, wobei ihnen ein möglicherweise erwirtschafteter Mehrwert ausdrücklich zugesichert wird. Um den Unterschlagungen der actores vorzubeugen, heißt es dann weiter, solle die Abgabenerhebung von nun an dem Statthalter und seiner Behörde obliegen. Zuletzt ordnet der Kaiser im fünften Abschnitt (Z. 19-24) noch die Erstellung eines umfassenden Katasters an, welches ein offenbar bereits existierendes (Z. 3; 12f.) dadurch vervollständigen soll, daß es exakte Angaben über die Pachtverhältnisse auf jeder einzelnen Parzelle verzeichnet.

Auf den ersten Blick scheint die herkömmliche Deutung der Inschrift recht zu behalten: Der Konstitution muß eine Konfiskation der betroffenen fundi rei publicae vorausgegangen sein, die Städte hatten nach Eutrops Reform zwar nicht das Eigentum, wohl aber die Direktverwaltung jener Güter inne, und ihre Einkünfte wurden zwischen Fiskus und Stadt aufgeteilt. Stutzig machen allerdings einige Beobachtungen, die Zweifel aufkommen lassen, ob die 
fundi rei publicae der Inschrift tatsächlich die Gesamtheit des städtischen Grundbesitzes der Provinz Asia meinen können. In Z. 14-16 beziffert das Dokument den Umfang der betroffenen fundi auf 6736 iuga ertragbringenden und 703 inga brachliegenden Landes, also auf insgesamt etwa 7440 inga. ${ }^{53}$ Für das gesamte Gemeindeland der Provinz erscheint diese Zahl äußerst gering, wenn man bedenkt, daß Julian der Stadt Antiochien $3000 \kappa \lambda \hat{\eta} \rho o r$ bzw. iuga Land nur zur Aufzucht von Rennpferden überlie $\beta^{54}$ und daß allein das Territorium der syrischen Kleinstadt Kyrthos 10.000 inga im Besitz der res privata umfaßte; 55 andere Zahlen ließen sich ergänzen. ${ }^{56}$ Diese Angaben sind gewiß nicht direkt vergleichbar, weil das ingum als Steuerhufe zumindest in Syrien mit je nach Qualität und Produkt des Bodens unterschiedlichen Schlüsseln berechnet wurde, also jeweils einer höchst unterschiedlichen realen Bodenfläche entsprach. ${ }^{57}$ Außerdem ist weder die Zusammensetzung der verglichenen Territorien in bezug auf die Qualität ihrer Güter bekannt noch, ob das ingum in Asia überhaupt nach demselben Modus mit denselben Schlüsseln berechnet wurde. Dennoch: Nur mit extrem divergierenden Steuerhufen und Bodenbedingungen ließe sich erklären, daß der gesamte städtische Grundbesitz einer stark urbanisierten Provinz wie Asia nicht einmal 7500, aber allein die

53 Deren Einkünfte das Dokument in Z. 15f. ebenfalls beziffert. Leider ist die entscheidende Textstelle korrupt; auf dem Stein steht statt einer Zahl ein an dieser Stelle sinnloses VINVM. Keiner der diversen Emendationsversuche kann ein zwingendes Argument für sich vorbringen.

54 Iul. Mis. 370D-371B; in 362D wird außerdem erwähnt, Antiocheia besitze $\mu$ víous

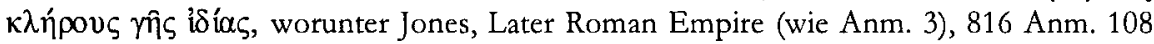
allerdings keine Zahlenangabe (10.000 iuga) erkennen will, sondern ein unspezifisches "sehr viele Landlose“. Zur Verwendung des Begriffs $\kappa \lambda \hat{p} \rho \varsigma_{\varsigma}$ für iugum an dieser Stelle vgl. J. Gascou, KАHPOI AПOPOI (Julien, Misopogôn 370D-371B), BIAO 77, 1977, 235-255.

55 Von 62.000 inga des Gesamtterritoriums: Thdt. Ep. Sip. 42 und 47 ed. Azéma; der große Umfang der Domänen mag darauf zurückzu führen sein, daß der Usurpator Avidius Cassius (gegen Mark Aurel) aus Kyrrhos stammte.

56 Weitere Zahlen bei Jones, Later Roman Empire (wie Anm. 3), $815 f$.

57 Die Berechnungsmodalitäten des syrischen ingum sind aus dem syrisch-römischen Rechtsbuch bekannt: FIRA II, S. 795f;; z. B. entsprechen 1000 itga entweder 5000 iugera Weinland oder 40.000 iugera minderwertigen Ackerlandes, also einer bis um das Achtfache größeren Bodenfläche. Schlüssel für die afrikanische centuria sind nicht bekannt, ebensowenig, wie iuga und centuriae miteinander korrelierten. Die von A. H. M. Jones, Census Records of the Later Roman Empire, JRS 43, 1953, 49-64, hier: 49f.; (= ders., The Roman Economy [hg. von P. A. Brunt], Oxford 1974, 228-256, hier: 228f.) errechneten Schlüssel für das ingum in Asia beruhen auf einer in ihrer Deutung höchst umstrittenen, teilweise ergänzten Inschrift. 
Besitzungen des Fiskus in einer unbedeutenden Provinzstadt Syriens 10.000 iuga umfaßten; das erscheint insgesamt ziemlich unwahrscheinlich.

Weitere Beobachtungen bestärken die Zweifel daran, daß die fundi rei publicae der Inschrift das gesamte Gemeindeland der Provinz meinen. Warum sollte Eutrop, wenn seine Maßnahme den gesamten städtischen Grundbesitz betroffen hätte, den Grundbesitz ,nach eigenem Ermessen“, wie es in Z. 17 heißt, also offenbar ganz neu verteilen? Die einzige praktikable Lösung wäre dann doch wohl diejenige gewesen, den administrativen Status quo ante wiederherzustellen, also den Städten ihren ursprünglichen Besitz zur Verwaltung zu geben. Nicht recht passen will auch die Notwendigkeit, ein umfassendes Kataster anlegen zu lassen, weil offenbar so elementare Dinge wie Pächtername, Pachtstatut und Abgabenhöhe unklar waren. Solche Unklarheiten sind nur denkbar, wenn die Besitzverhältnisse massiv gestört waren. Dann würde man die umfassende Katastrierung des städtischen Grundbesitzes allerdings zum Zeitpunkt der Konfiskation annehmen wollen, nicht erst Jahre später.

Viel besser lassen sich diese Bestimmungen verstehen, wenn man von der Deutung der fundi rei publicae als des gesamten Gemeindelandes der Provinz Abstand nimmt und sie stattdessen mit einer anderen Gütermasse identifiziert: den fundi iuris templorum, dem Tempelland. Dieser Vorschlag kann ein starkes Argument für sich in Anspruch nehmen: Im Falle des Tempelbesitzes ist es tatsächlich sicher verbürgt, daß Valentinian und Valens Julians Restitutionen gleich zu Beginn ihrer Herrschaft rückgängig machten und das Tempelland wieder konfiszierten. In CTh 10, 1, 8, gegeben am 4. September 364 in Mediana an den comes rerum privatarum des Valens, Caesarius, ${ }^{58}$ ist die entsprechende Verfügung für die östliche Reichshälfte überliefert, in CTh 5, 13, 3, gegeben am 23. Dezember diesen Jahres in Mailand an den Präfekten Claudius Mamertinus, die für den Westen:

Universa, quae ex patrimonio nostro per arbitrium divae memoriat Iuliani in possessionem sunt translata templorum, sollicitudine sinceritatis tuae cum omni iure ad rem privatam nostram redire mandamus.

Alles, was aus Unserem Besitz auf Anordnung Julians seligen Angedenkens in den Besitz der Tempel übertragen wurde, soll, so lautet Unser Auftrag, durch den Eifer Deiner Redlichkeit zu vollem Besitz an die res privata zurückgehen.

58 Die Identifizierung des Ausstellungsortes und Adressaten der Konstitution sowie die hier gegebene Datierung unterscheiden sich erheblich von den bisher in der Forschung vertretenen Auffassungen: Vgl. dafür die Marburger Dissertation des Verfassers (wie Anm. 4). Übersetzt wird hier nur CTh $5,13,3$. 
Die Rekonfiskation durch Valentinian und Valens bezog sich übrigens tatsächlich nur auf die von Julian restituierten Tempelgüter, denn noch bis ins frühe fünfte Jahrhundert scheint es unabhängiges Tempelland gegeben zu haben. 59

$\mathrm{Da}$ die ephesische Inschrift die betroffenen Tempelgüter als fundi rei publicae bezeichnet, widerspricht der Identifikation mit dem Tempelland nicht: Wie im Falle des angeblichen Restitutionsgesetzes Julians mag auch in diesem Fall die mangelnde terminologische Prägnanz dem konkreten Entstehungszusammenhang des Textes geschuldet sein, denn das Dokument war das Resultat eines langwierigen Verhandlungsprozesses zwischen Stadt, Prokonsul und Kaiser, an dessen Ende allen Beteiligten die Identität der betroffenen Liegenschaften vertraut gewesen sein dürfte. Abgesehen davon ist die Bezeichnung der Tempelgüter als fundi rei publicae sachlich richtig und war zudem gebräuchlich: Die meisten Heiligtümer lagen in Stadtbesitz, und nicht nur Julians Restitutionsgesetz nennt sie, wie oben gezeigt, possessiones publicae. ${ }^{60} \mathrm{Im}$ Kontext des wechselvollen Schicksals des Tempellandes überzeugt im übrigen auch die Notwendigkeit eines neuen Katasters vollauf: Julians Maßnahme hatte eine Entwicklung rückgängig zu machen versucht, die mit größeren Enteignungen Konstantins begonnen hatte und unter seinen Nachfolgern fortgesetzt worden war; besonders Constantius II. wurde vorgeworfen, seine Günstlinge mit Tempelland geradezu ,gemästet“ zu haben. ${ }^{61} \mathrm{Als}$ Julian diese Güter den Heiligtümern oder Städten restituierte - übrigens wie hier mit der Maßgabe, die Einkünfte für Baumaßnahmen zu nutzen -, wird es vielfach auch zu einem Wechsel jener Besitzer (Pächter) gekommen sein, die bei Julian in Ungnade gefallen waren. ${ }^{62}$

Im Zuge der Rekonfiskation dieser Güter im Jahre 364 ist von einem erneuten Eingriff in die Besitzstrukturen nicht die Rede, und in der Tat wäre er den Absichten Valentinians und Valens' zuwidergelaufen, denen es zuvör-

59 In Symm. Ep. 1, 68 (380) wird ein Gut im Besitz der stadtrömischen pontifices erwähnt; eine weitere Enteignungswelle scheint um das Jahr 382 stattgefunden zu haben (CJ 11, 66, 4; CTh 10, 3, 4; Ambr. Ep. 73, 16 ed. Zelzer), und noch im Jahre 415 ergingen Erlasse zur Konfiskation der Tempelgüter (CTh 16, 10, 20); vgl. allgemein zur Enteignung der Tempelgüter in der Spätantike Delmaire, Largesses sacrées (wie Anm. 4), 693f. und die oben in Anm. 24 gegebenen Literaturve rweise.

60 Vgl. oben Anm. 22.

61 S. oben Anm. 24 und die folgende Anm.

62 Nach Amm. 22, 4, 3 säuberte Julian den Hofstaat von Elementen, die pasti enim ex his quidam templorum spoliis, "gemästet aus der Beute der Tempel“, zu ungeheurem Reichtum gekommen waren. 
derst um die komplikationslose, rasche Erschließung einer Geldquelle für den durch Julians Perserfeldzug ruinierten Staathaushalt gehen mußte. Gleichwohl wird sich das im Laufe der Zeit geändert haben. Nach der Niederschlagung des Prokop-Aufstandes gerieten die Parteigänger Julians und überhaupt die altgläubige Elite in der Präfektur Oriens unter den Generalverdacht, in Opposition zu Valens zu stehen, was in der hysterischen Atmosphäre der Magieprozesse von Antiocheia im Winter 371/372 eine blutige Kulmination fand. Viele Nutznießer der julianischen Tempelgüterrestitution dürften zu den Betroffenen dieser Kampagne gehört haben. Umgekehrt herrschte nun ein günstiges Klima für die Verlierer der julianischen Restitution, die nun, nach sieben oder acht Jahren, Hoffnung schöpfen konnten, die Verluste unter Julian wieder auszugleichen und alte Besitztümer zurückzuerlangen. Es gibt also gute Gründe, warum es Valens in der ephesischen Epistel just in dem Zeitraum, in dem die Spannung eskalierte, für nötig erachten konnte, die Besitzverhältnisse auf Ländereien zu klären, die aus dem Eigentum heidnischer Heiligtümer stammten. Bezeichnenderweise firmiert in den Quellen vor allem Kleinasien als der Raum, in dem es zu regelrechten Verfolgungen der Altglä ubigen kam. ${ }^{63}$

Die hier vorgeschlagene, neue Deutung der Inschrift kann also gute Argumente für sich in Anspruch nehmen. Sie läßt sich folgendermaßen resümieren: Valens ermächtigte Eutrop, den einige Jahre zuvor rekonfiszierten, eigentlich aber schon seit Konstantin in Staatshand befindlichen Grundbesitz der Tempel in der Provinz Asia in die Verwaltung der Städte zu übertragen. Vom Gemeindeland in seiner Gesamtheit ist hier nicht die Rede, und wieder wäre es fahrlässig, aus den besonderen Bedingungen der Tempellandkonfiskation in der aufgeheizten Stimmung nach Julians Tod auf eine globale Enteignung städtischen Grundeigentums schließen zu wollen.

Was bedeutet dieses Ergebnis für die Frage nach der städtischen Finanzautonomie? Mit der Neuinterpretation der ephesischen Inschrift fällt das einzige Zeugnis für die These, Valentinian und Valens hätten im Jahr 364 eine globale Enteignung der städtischen Einnahmequellen durchgeführt. Damit gibt es keinen einzigen Anhaltspunkt mehr für die communis opinio der Forschung, daß die städtischen Einkünfte jemals konfisziert, also in das Eigentum der res privata überführt worden oder wenigstens zur Gänze in staatliche Verwaltung übergegangen seien. Eine globale Konfiskation gab es also nie, und so erklärt sich auf die denkbar einfachste Weise, weshalb sie nir-

63 Ausführliche Schilderung bei F. J. Wiebe, Kaiser Valens und die heidnische Opposition, Bonn 1995, 131 -148; Lenski, Failure of Empire (wie Anm. 51), 223-234. 
gendwo belegt ist, und weshalb im Gegenteil noch Generationen später Städte als Eigentümer und mit Verfügungsgewalt über Liegenschaften und Abgaben begegnen.

Die Quotierung der Einkünfte in den 370er Jahren ebenso wie zahlreiche, oben vorgeführte Quellenaussagen belegen allerdings auch, daß Städte und Fiskus gleichermaßen über munizipale Einkommensquellen verfügen konnten. Die Frage nach Umfang und Gestalt der städtischen Finanzautonomie in der Spätantike und damit auch nach der Einordnung der Quotierungsregel unter Valentinian und Valens besteht also weiterhin - auch wenn gezeigt werden konnte, daß die Hypothese einer Enteignung dabei in die Aporie führt. Eine Antwort liefert der folgende Abschnitt.

\section{Stadt und Staat in der römischen Kaiserzeit}

Da mit der Konfiskation auch eine vermeintliche Zäsur in der Geschichte der munizipalen Finanzverwaltung wegfällt, ist das Verhältnis von Stadt und Staat in diesem Bereich nur dann zu verstehen, wenn man die Entwicklungen der spätrömischen Zeit in Beziehung setzt zu ihren prinzipatszeitlichen Voraussetzungen. Denn in der Tat läßt sich bereits in der Prinzipatszeit beobachten, $\mathrm{da} ß$ die kaiserliche Finanzverwaltung in zunehmendem Maße in die städtische Finanzwirtschaft eingriff. Einige Hinweise müssen hier genügen: Anfang des zweiten Jahrhunderts beginnt die zunächst punktuelle, dann immer weiter um sich greifende Einsetzung von curatores rei publicae, die als kaiserliche Kontrollbeamte für die städtischen Haushalte umfassenden Einfluß auf die Finanzwirtschaft der Städte nehmen konnten. ${ }^{64}$ Mehrmals begegnen Eingriffe der Statthalter in die (Finanz-) Verwaltung städtischer Ländereien; Ulpian folgerte daraus sogar eine Dienstpflicht des Statthalters, sich um die Optimierung der Einkünfte von städtischen Ländereien zu kümmern. ${ }^{65}$ Seit Vespasian begegnen Quellen, nach denen jede Veränderung des städtischen Steuerwesens durch Einführung oder Abschaffung von Steuern oder selbst nur eine Anleihe unter den Bürgern der Stadt einer kaiserlichen Ermächtigung bedurfte. ${ }^{66}$

64 Vgl. unten Anm. 70 f.

65 Dig. 50, 10, $5 \backslash 1$ : curabit praeses provinciae ... publicos potius reditus angere, Beispiele für die Verpachtung städtischer Ländereien durch den Statthalter in AE 1967, 531 (73-75 n. Chr., Apollonia in der Cyrenaica) und Syll. ${ }^{3} 884$ (Thisbe); vgl. auch die unten in Anm. 70 genannte Literatur.

66 CIL II $1421=$ ILS 6092 = FIRA I 74, wo Vespasian die Einführung neuer Steuern durch die Stadt Sabora an eine Genehmigung des Prokonsuls bindet; spätere Beispiele kaiserli- 
Ein wichtiger Aspekt der Mission des jüngeren Plinius in der Provinz Bitbynia et Pontus bestand in der Überprüfung der munizipalen Rechnungsbücher, meist im Zusammenhang mit Bauvorhaben der Städte; Plinius erfüllte damit Aufgaben eines kaiserlichen Sonderbeauftragten mit dem Titel legatus bzw.

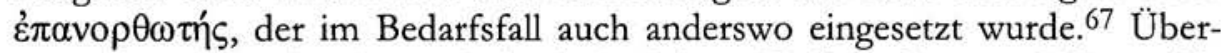
haupt läßt sich das Ausmaß der kaiserlichen Einflußnahme auf die städtischen Finanzen im Bereich des Bauwesens besonders gut verfolgen: Vor allem juristische Texte zeigen, daß seit Ende des ersten Jahrhunderts die $\mathrm{Zu}$ stimmung des Statthalters, später des Kaisers selbst, unabdingbare Voraussetzung städtischer Bauvorhaben wurde, weil man auf diese Weise verhindern wollte, daß sich die Städte durch überzogene Projekte ruinierten. ${ }^{68}$ Die Eingriffe der kaiserlichen Verwaltung gingen dabei so weit, daß Gelder, die testamentarisch für Baumaßnahmen bestimmt waren, für Restaurierungsarbeiten umgewidmet werden konnten. ${ }^{69}$

Diese Entwicklungen dürfen freilich nicht mit einer Tendenz zur totalen Kontrolle der Städte und dem vollkommenen Entzug ihrer Finanzautonomie durch die kaiserliche Verwaltung gleichgesetzt werden, wie dies die eingangs skizzierte, mit dem Namen Wilhelm Liebenams verbundene Forschungstradition will. Diese Auffassung wird in der Forschung ganz im Gegenteil mittlerweile grundsätzlich in Zweifel gezogen. So versteht man das Amt des curator rei publicae heute nicht mehr als Versuch, eine flächendeckende kaiserliche Kontrollinstanz in den Städten zu installieren. Die Quellenlage wird heute

cher oder statthalterlicher Ermächtigungen in SEG XXXVIII 1462, Z. 115f. (Oinoanda); L. Robert, Hellenica 6, Paris 1948, 81 Nr. 26, I, Z. 9f. (Hadrianopolis-Stratonikeia); IG-Bulg. IV 2263; die Zollinschrift von Palmyra CIS II 3913 mit J. Matthews, The Tax Law of Palmyra, JRS 74, 1984, 157-180; CJ 4, 62, 1-3; Dig. 39, 4, 10; Anleihen über eine gewisse Höhe sind genehmigungspflichtig durch den Statthalter nach der Lex Imitana 80 ed. J. Gonzalez, JRS 76, 1986, 174.

67 Plin. Ep. 10, 18;10, 37; 10, 39; 10, 43; 10, 47; 10, 77; 10, 90; 10, 92; 10, 98, meist im Zusammenhang ruinöser Bauvorhaben. Eine Liste weiterer Legaten mit wohl ähnlichem Auftrag bei B. Thomasson, Legatus. Beiträge zur römischen Verwaltungsgeschichte, Stockholm 1991, 80-84; vgl. A. Kolb, Die Einflußnahme des Kaisers auf das städtische Bauwesen, in: R. Frei-Stolba/H. E. Herzig (Hgg.), La politique édilitaire dans les provinces de l'Empire romain. IIème-IVème siècles après J.-C. Actes Berne 1993, Bern u. a. 1995, 272-282, hier: 276-279, sowie W. Eck, Der Kaiser, die Führungsschichten und die Administration des Reiches (von Vespasian bis zum Ende der antoninischen Dynastie), in: ders., Die Verwaltung des Römischen Reiches in der Hohen Kaiserzeit, Bd. 2, Basel 1998, 3-145, hier: $127 \mathrm{f}$.

68 A. Kolb in: Frei-Stolba, Politique édilitaire (wie Anm. 67), 273-276.

69 So z. B. Dig. 50, 10, 7 (Kallistrat); CIL IX 5746 = ILS 5675 (Ricina); IRT 396 (Lepcis Magna). 
vielmehr so gedeutet, daß Kuratoren nur bei Bedarf eingesetzt wurden und in der Regel nur eine lockere Aufsicht vornehmlich über Bausachen ausübten; ${ }^{70}$ oft kamen solche Maßnahmen dem Interesse der Städte entgegen oder erfolgten gar auf ihr Betreiben hin. ${ }^{71}$ Die neuere Forschung geht außerdem davon aus, daß in der gesamten Prinzipatszeit eine zumindest partielle Steuerund Zollhoheit der Städte existierte, die allenfalls einer engeren Aufsicht unterlag (wobei aber auch die volle Autonomie gelegentlich explizit belegt ist). ${ }^{72}$ Die auch in der Prinzipatszeit gelegentlich bezeugte Einflußnahme des Staatsapparates auf die Verwaltung der städtischen Ländereien wurde schon immer lediglich im Sinne einer Oberaufsicht, nicht als Tendenz zu totaler Appropriation gewertet. ${ }^{73}$ Und nicht zuletzt wird die Bedeutung des Euergetismus und anderer Formen der Finanzierung städtischer Aufgaben aus privaten Geldern, die in der Forschung lange deswegen als besonders wichtig galten, weil man sie als die einzige Möglichkeit der Städte ansah, den Verlust der Verfügungsgewalt über Steuern und Abgaben auszugleichen, heute ebenfalls zunehmend relativiert. Die regulären Einkommensquellen scheinen demnach weiterhin für den Großteil des städtischen Finanzbedarfs zur Verfügung gestanden zu haben. ${ }^{74}$

70 Zum neuen Bild des Kuratorenamtes R. Duthoy, Curatores rei publicae en Occident durant le Principat, AS 10, 1979, 171-238; G. P. Burton, The curator rei publicae: towards a reappraisal, Chiron 9, 1979, 465-487; G. Camodeca, Ricerche sui curatores rei publicac, in: ANRW II 13, 1980, 453-534; F. Jacques, Les curateurs de cités dans l'Occident romain de Trajan à Gallien, Paris 1983; M. Sartori, Osservazioni sul ruolo del curator rei publicae, Athenaeum n. s. 67, 1989, 5-20 sowie zuletzt Eck in: ders., Verwaltung (wie Anm. 67), 128-131; Ch. Witschel, Krise - Rezession - Stagnation? Der Westen des Römischen Reiches im 3. Jahrhundert n. Chr., Frankfurt/Main 1999, 129-132.

71 P. Herrmann, Kaiserliche Garantie für private Stiftungen. Ein Beitrag zum Thema „Kaiser und städtische Finanzen“", in: W. Eck u. a. (Hgg.), Studien zur antiken Sozialgeschichte. Festschrift Friedrich Vittinghoff, Köln 1980, 339-356.

72 M. Corbier, City, Territory and Taxation, in: J. Rich ( $\mathrm{Hg})$, City and Country in the Ancient World, London 1991, 211-240 (u. ö. zuvor); G. P. Burton, Was there a long-term trend towards centralisation of authority in the Roman empire?, $\mathrm{RPh} 72$ 1998, 7-24, hier: 10-13; J. France, Les revenues douaniers des communautés municipales dans le monde romain (République et Haut-Empire), in: Finanze municipali (wie Anm. 4), 95-113; P. Le Roux, Vectigalia et revenus des cités en Hispanie au Haut-Empire, ebd. 155-173 und andere Beiträge dieses Sammelbandes; Merola, Autonomia locale (wie Anm. 4), 121-134 + 139-141; H. Schwarz, Soll oder Haben? Die Finanzwirtschaft kleinasiatischer Städte in der Römischen Kaiserzeit am Beispiel von Bithynien, Lykien und Ephesos (29 v. Chr.284 n. Chr.), Bonn 2001 mit der Rezension von L. Migeotte, Gnomon 76, 2004, 341-344.

73 Quellen bei Burton, RPh 32, 1998 (wie Anm. 72), 13-16.

74 W. Eck, Der Euergetismus im Funktionszusammenhang der kaiserzeitlichen Städte, in: M. Christol/O. Masson (Hgg.), Actes du Xe Congrès international d'épigraphie 1992, 
Das Modell, daß die Geschichte der munizipalen Finanzautonomie in der Prinzipatszeit von einer klaren Tendenz zur Monopolisierung durch die Staatsgewalt geprägt gewesen sei, ist also mit Sicherheit zu schematisch. Dieser Befund gilt auch für die Spätantike. Ohne jeden Zweifel finden sich unzählige Belege für eine Kontrolle des städtischen Finanzgebarens durch den Fiskus: So betraute die bereits erwähnte Konstitution Konstantins, die durch eine Inschrift aus Orkistos überliefert ist, einen rationalis, also einen Beamten des Fiskus, mit der Aufsicht darüber, daß die Stadt Nakoleia keine Abgaben mehr von der Gemeinde Orkistos erhob; offenbar gehörte die Kontrolle der lokalen Steuererhebung also zu den Aufgaben der Finanzverwaltung. In den 350er Jahren lagen die Naturaleinkünfte vom Gemeindeland des syrischen Antiocheia in der Verantwortung von Speicherverwaltern, die den Provinzialbehörden unterstanden und die städtischen Bediensteten - wenn man Libanios glauben darf - in demütigender Weise um die Ausgabe ihres Lohns betteln ließen. ${ }^{75}$ Eine Fülle von Konstitutionen insbesondere im Titel 15, 1 des „Codex Theodosianus“ zeigt, daß das munizipale Bauwesen als zweifellos größter Posten der städtischen Haushalte in der Spätantike einer strikten Aufsicht durch die Statthalter unterlag, ${ }^{76}$ und der epigraphische Befund bestätigt das insofern, als der Statthalter nun immer als Hauptakteur bei städtischen Baumaßnahmen firmiert. ${ }^{77}$ Eine ihrem Inhalt nach einmalige Inschrift aus Chalkis, die einen Erlaß des Statthalters der Provinz Acbaia aus dem Jahr 359 überliefert, zeigt, daß dieser die Verantwortlichen, die Materialien, die

Nîmes 1997, 305-331; Witschel, Krise (wie Anm. 71), 129-132 mit Anm. 131; S. Cramme, Die Bedeutung des Euergetismus für die Finanzierung städtischer Aufgaben in der Provinz Asia, Diss. Köln 2001.

75 Lib. Or. 31, 16-20; genannt wird die Behörde des Statthalters (die åp $\chi 0 v \tau \varepsilon \varsigma$ und ihre

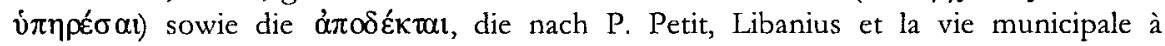
Antioche au IVe siècle après J.C., Paris 1955, 153f. und Liebeschuetz, Antioch (wie Anm. 4), 88 den praepositi horreorum entsprechen, d. h. liturgischen Verwaltern der Getreidemagazine unter Aufsicht der Provinzstatthalter.

76 Allg. für diese Zuständigkeit der Statthalter zuletzt A. Kolb in: Frei-Stolba, Politique édilitaire (wie Anm. 68), 279-281; Lepelley in: Finanze municipali (wie Anm. 4) sowie A. Lewin, Urban Public Building from Constantine to Julian: the Epigraphic Evidence, in: L. Lavan (Hg.), Recent Research in Late-Antique Urbanism, Portsmouth 2001, 27-37; vgl. auch das oben genannte Dossier von 395, CTh 15, 1, 18 sowie den folgenden Abschnitt des Kapitels.

77 Ein Katalog epigraphisch bezeugter Baumaßnahmen in Städten in der Osthälfte des Reiches von Diokletian bis Theodosius bei A. Lewin, Studi sulla città imperiale Romana nell'Oriente tardoantico, Como 1991, 117-135; für Afrika bei Lepelley, Cités de l'A frique (wie Anm. 4), 112-120. 
Finanzierung und andere Details einer Baumaßnahme genehmigen mußte,

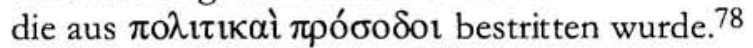

Die Beispiele ließen sich fortsetzen. Aus ihnen allen geht zwar nicht die Konfiskation der städtischen Einkünfte hervor, aber doch die enge Überwachung der städtischen Finanzverwaltung durch die kaiserliche Bürokratie. Gleichwohl zeigen die oben vorgeführten Quellen in unzweideutiger Weise, daß die Städte auch in der Spätantike eine zumindest teilweise unabhängige Verwaltung von Ländereien und Steuereinkünften ausüben konnten. Noch im sechsten Jahrhundert begegnen Konstitutionen, die den Staatsorganen einschärfen, sich nicht in die Finanzverwaltung der Städte einzumischen. ${ }^{79}$ Und die ephesische Inschrift ist ebenso wie die oben bereits erwähnte Konstitution CJ 11, 70, 6 über das ius exactionis einiger Güter der Stadt Nikaia ein Beispiel dafür, daß der Staat seine Einflußnahme auf die städtische Finanzautonomie durch die Rückführung von Liegenschaften in autonome städtische Verwaltung bisweilen durchaus zurücknehmen konnte. Weiterhin darf die Tatsache, daß der Statthalter eine Oberaufsicht über Bausachen führte, nicht $\mathrm{zu}$ dem Schluß verleiten, daß es keinerlei städtisch initiierte und finanzierte Bauprojekte mehr gegeben habe; das Formular einiger Bauinschriften und manch andere Indizien deuten in der Tat auf das Gegenteil. ${ }^{80}$ Und auch wenn bestimmte Anteile der städtischen Einkünfte, seit den 370ern zwei Drittel, vom Fiskus verwaltet wurden, bedeutet das im übrigen ja keineswegs, $\mathrm{da} ß$ er sie einbehielt und nicht-städtischen Zwecken zuleitete. Im Gegenteil waren regelmäßige Zuweisungen von Geldern durch den Fiskus für städtische Belange, vor allem Bausachen, - beispielsweise ein Viertel gewisser vectigalia (CTh 14, 3, 5, 358) oder vectigalia ad angustiarum solacia (CJ 4, 61, 10, 405408) - üblich und sind dicht dokumentiert. ${ }^{81}$ Nichts spricht dagegen, daß solche Gelder aus städtischen Einkünften stammten.

Nicht nur die Konfiskationsthese führt also in die Irre. Ebensowenig wie in der Prinzipatszeit wurde in der Spätantike die eigenständige Finanzverwaltung der Städte vollständig unterdrückt. Stattdessen geht aus der wider-

78 Syll. $^{3}$ 905 = IG XII 9, 907; vgl. dazu A. Lewin, Il dossier di Publio Ampelio, AARC 13, 2001, 621-646.

79 Z.B. CJ 8, 12, 1 (485/6); 1, 4, 26 \ 4 (530); 10, 30, 4 (530); NJust 17, 4 (535); 25, 4 (535); 30,8 (536); 128, 16 (545). Es ist in diesem Zusammenhang unerheblich, ob die Gelder aus städtischen Einkünften stammten oder den Gemeinden vom Staat zugewiesen worden waren.

80 Lepelley in: Finanze municipali (wie Anm. 4), bes. 237-240; so auch Lewin in: Lavan, Late Antique Urbanism (wie Anm. 76), 30f., freilich ohne stichhaltige Belege.

81 Außer den genannten Quellen z. B. CTh 9, 17, 2; 15, 1, 48; CJ 1, 4, 26; 10, $30,4$. 
sprüchlichen Quellenlage eher ein kompliziertes, offenbar je nach Haushaltsposten, Stadt und Zeitumständen ganz unterschiedlich geartetes Wechselspiel von Fiskus und Gemeinde hervor, das keinem reduktionistischen Globalmodell unterworfen werden darf. Das Postulat eines totalen Verlustes der Finanzautonomie und der vollständigen Expropriation der Städte von Steuern, Zöllen, Pachtzinsen etc. muß also aufgegeben werden. Dennoch bleibt es sicherlich richtig, daß die kaiserliche Finanzverwaltung spätestens seit dem zweiten Jahrhundert in zunehmendem Maße Einfluß auf das Finanzgebaren der Gemeinden nahm und dabei auch manche Einkünfte ihrer direkten Regie unterstellte. In der späten Kaiserzeit setzt sich diese Tendenz fort, zweifellos befördert durch den gewaltigen Staatsapparat, der die administrativen Voraussetzungen dafür stärkte, und auch durch den Autonomieverlust, der sich beispielsweise in der Nivellierung der unterschiedlichen munizipalen Rechtsstatute oder in der Unterbindung einer eigenständigen Münzprägung ausdrückte. Die Einflußnahme des Staates auf das Finanzwesen dürfte sich in spätrömischer Zeit in summa also verstärkt haben, doch blieb diese Einflußnahme, so läßt sich resümieren, immer punktuell und je nach Situation von unterschiedlicher Intensität. Zu einer Totalenteignung kam es dabei nie.

Dieses Szenario besitzt gegenüber den bisherigen Versuchen, die Quellenlage in ein reduktionistisches Modell zu pressen, mehrere Vorzüge. Erstens kann es auf das durch die Quellenlage nicht zu rechtfertigende Postulat einer Globalkonfiskation der städtischen Einkünfte verzichten. Zweitens vermag es dieser Lösungsansatz im Gegensatz zu den bisher unterbreiteten, alle gegebenen Quelleninformationen zu inkorporieren, und ist dabei zugleich flexibel genug, um erstmals alle Widersprüche der Quellenlage in einem befriedigenden Modell vereinen zu können. Drittens schließt dieses Modell an aktuelle Ansätze zur Neubewertung des Problems der munizipalen Finanzautonomie in der Prinzipatszeit an, indem es deren Erkenntnis, daß ein systematisches Bestreben zur Zentralisierung der Finanzhoheit niemals existierte, durch den Nachweis untermauert, daß der Endpunkt, auf den diese Entwicklung vermeintlich zulief, der Konfiskationsakt, ein modernes Konstrukt darstellt.

Damit ist der Hintergrund gegeben, vor dem schließlich auch die Quotierungsregel Valentinians und Valens' gedeutet werden muß. Unzweifelhaft kommt darin, daß sie zwei Drittel der städtischen Einkünfte der Regie des Fiskus unterstellte, eine massive staatliche Kontrolle des städtischen Finanzgebarens zum Ausdruck. Das ist jedoch nur eine Seite der Medaille. Denn die Quotierungsregel definiert umgekehrt auch einen Anteil, über den die Gemeinden fortan vollkommen eigenständig verfügen konnten. Das geht so weit, daß den staatlichen Finanzbehörden die Einmischung explizit verboten 
wird: Im Jahre 431 wiederholt die schon mehrmals erwähnte Konstitution CJ 4, 61, 13 an Nicomachus Flavianus die Quotierungsregel und betont dabei ausdrücklich das Recht der Städte, das Drittel aus dem Grundbesitz, das sich in ihrer Verwaltung befindet, eigenständig zu verpachten. Denn, so heißt es in dem oben bereits zitierten zweiten Abschnitt, ,jenes Drittel soll so weitgehend der Verfügungsgewalt der Städte und Kurialen unterstehen, daß sie wissen, $d a ß$ die Verantwortung für ihren eigenen Vorteil eher in ihrer eigenen Entscheidungsgewalt als in derjenigen eines anderen (nämlich des Fiskus) gründet". Auch die ephesische Inschrift rückt in diesem Zusammenhang noch einmal ins Blickfeld: Dort wird ja ausdrücklich das Ziel formuliert, die Städte in bezug auf die Verwaltung bestimmter Liegenschaften fortan vom bürokratischen Apparat, seiner Schwerfälligkeit und seiner Korruptionsanfälligkeit unabhängig zu machen. Die Quotierungsregel ist insofern keineswegs nur das Produkt gesteigerter staatlicher Einflußnahme, sondern muß auch im Kontext einer in den späten $360 \mathrm{er}$ und 370er Jahren offenbar in diversen Einzelsituationen verfolgten Programmatik gesehen werden, den Städten einen größeren, autonomen finanziellen Handlungsspielraum zu geben.

Damit erscheint die von Valentinian und Valens beschlossene Teilung der Verantwortung für die Verwaltung der städtischen Einkünfte zwischen Stadt und Fiskus in gänzlich neuem Licht: Zum ersten Mal - wenigstens nach Ausweis der Überlieferung - in einer über zweihundertjährigen Geschichte ständig zunehmender, aber ohne erkennbare Regelhaftigkeit erfolgender Einflußnahme des Kaisers auf das städtische Finanzwesen wurden die Kompetenzen von Fiskus und Stadt in allgemeingültiger Weise definiert. Dabei ging es nach dem Zeugnis der genannten, programmatischen Aussagen weniger um eine Beschränkung der Städte als vielmehr darum, eine (zumindest partielle) Finanzautonomie der Städte dauerhaft festzuschreiben. Den Gemeinden wurde auf diese Weise ermöglicht, über die vom Kaiser und seinen Vertretern genehmigten und gegebenenfalls finanzierten Ausgaben hinaus in einem beschränkten, aber verläßlichen Rahmen - autonome finanzielle Entscheidungen zu treffen, ohne beständig mit staatlichen Behörden Rücksprache halten oder Änderungen der Budgetsituation befürchten zu müssen.

Auch für den Fiskus war diese Regelung im übrigen vorteilhaft: Wie die Inschrift von Ephesos sagt, entzog man mittels der Verwaltung größerer Gütermassen durch die Gemeinden korrupten Beamten eine Gelegenheit zu Unterschlagungen, ja man konnte sogar auf höhere Einnahmen hoffen; zugleich aber hatte man dadurch, daß der Staat weiterhin den größeren Teil der Einkünfte kontrollierte (was wie gesagt nicht heißt, daß er sie nur für seine Zwecke verwendete), das Risiko dabei minimiert. Überhaupt zeigt die Tatsache, daß den Städten nur ein Drittel der Einkünfte zur freien Verfügung 
überlassen wurde, wie unverzichtbar die Kontrolle des Staates über das Finanzgebaren der Gemeinden mittlerweile erschien. Insofern behält Valentinians Quotierungs regel trotz der hier vorgeschlagenen Neuinterpretation einen ambivalenten Charakter. Sie entspricht damit vollauf dem Bild, das die Untersuchung von der Geschichte der städtischen Finanzautonomie in der römischen Kaiserzeit ergeben hat.

Die Einsicht, daß die Quotierungsregel der 370er Jahre nicht auf den Entzug von Autonomierechten reduziert werden darf, sondern diese umgekehrt auch dauerhaft festschrieb, rundet das Gesamtergebnis dieser Untersuchung ab: Es fordert erstens dazu auf, einen bis heute als zentral angesehenen Faktor in der Entwicklung des spätantiken Städtewesens, den Verlust finanzieller Handlungsspielräume, einer grundsätzlichen Neubewertung zu unterziehen. Zweitens zwingt es dazu, die herkömmliche Auffassung, daß der spätrömische Staat als hochbürokratisiertes Staatswesen mit einer ausgeprägt zentralistischen und etatistischen Tendenz immer weniger Raum für eigenständiges politisches Handeln der Städte ließ, in einem zentralen Punkt zu relativieren. Drittens schließlich zeigt die Untersuchung ein weiteres Mal, daß die traditionelle Epochengrenze zwischen Prinzipatszeit und Spätantike den Blick auf die Gesamtentwicklung römischer Staatlichkeit in der Kaiserzeit verstellt: Wie so viele andere Problemfelder steht auch der spätrömische Antagonismus von Stadt und Staat im Bereich der Finanzautonomie in einer weit in die Prinzipatszeit zurückreichenden Kontinuitätslinie. Und umgekehrt erscheint jetzt auch die prinzipatszeitliche Stadtgeschichte in einem neuen Licht: Die Niedergangsthese steht nun mehr denn je zur Debatte. Der vermeintliche Endpunkt der Entwicklung nämlich, Enteignung und Totalverlust der Finanzautonomie unter Diokletian oder Konstantin, hat sich als Chimäre der Forschung erwiesen. 